\title{
Novel Silica-Based Ion Exchange Resin
}

\author{
Final Report \\ November 17, 1997
}

Work Performed Under Contract No.: DE-AR21-96MC33088

\author{
For \\ U.S. Department of Energy \\ Office of Fossil Energy \\ Federal Energy Technology Center \\ P.O. Box 880 \\ Morgantown, West Virginia 26507-0880
}

By

Eichrom Industries Inc.

8205 South Cass Avenue

Suite 107

Darien, Illinois 60564 


\section{Disclaimer}

This report was prepared as an account of work sponsored by an agency of the United States Government. Neither the United States Government nor any agency thereof, nor any of their employees, makes any warranty, express or implied, or assumes any legal liability or responsibility for the accuracy, completeness, or usefulness of any information, apparatus, product, or process disclosed, or represents that its use would not infringe privately owned rights. Reference herein to any specific commercial product, process, or service by trade

name, trademark, manufacturer, or otherwise does not necessarily constitute or imply its endorsement, recommendation, or favoring by the United States Government or any agency thereof. The views and opinions of authors expressed herein do not necessarily state or reflect those of the United States Government or any agency thereof. 


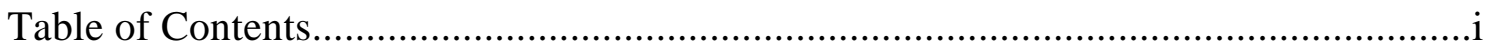

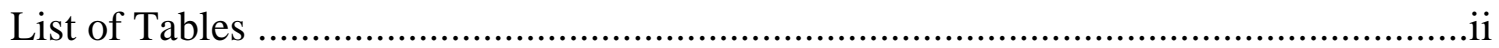

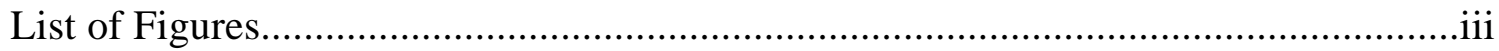

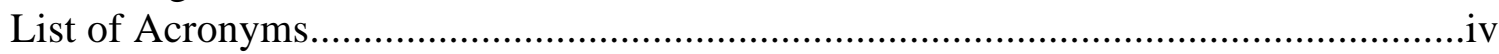

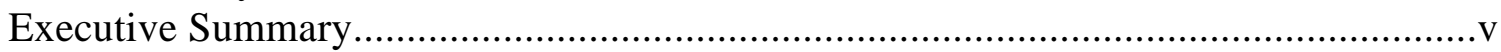

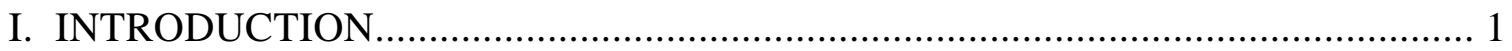

II. OBJECTIVES

III. EXPERIMENTAL - LABORATORY SCALE SYNTHESIS

Synthesis of vinyl modified silica gel (Silica-VS).............................................. 6

Synthesis of tetraisopropylvinylidene diphosphonate (VDPE) grafted

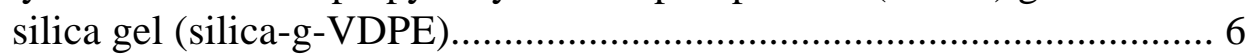

Hydrolysis of VDPE grafted silica gel............................................................ 7

Physical Properties Analysis........................................................................... 7

\section{RESULTS AND DISCUSSION OF LABORATORY SCALE SYNTHESIS}

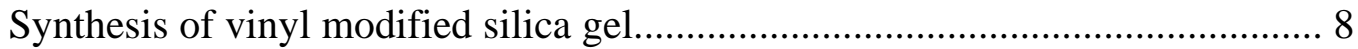

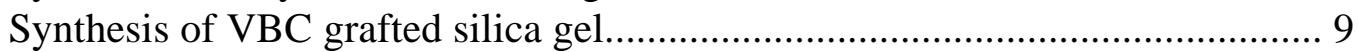

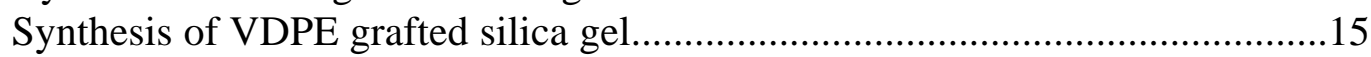

Hydrolysis of VDPE grafted silica gel..........................................................18

Physical Properties Evaluation........................................................................18

V. SCALE-UP

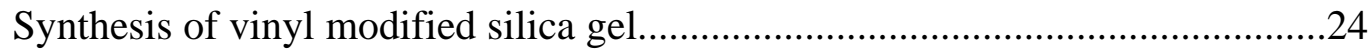

Synthesis and hydrolysis of vinyl modified silica gel..........................................28

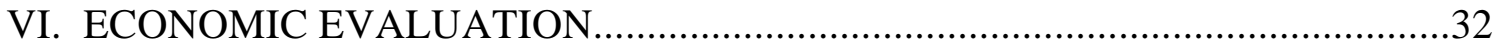

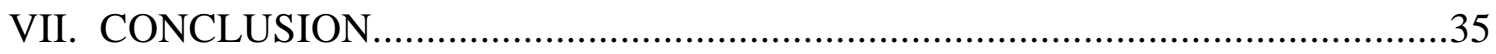

VIII. RECOMMENDATION FOR FUTURE WORK ................................................36

\section{APPENDICES}

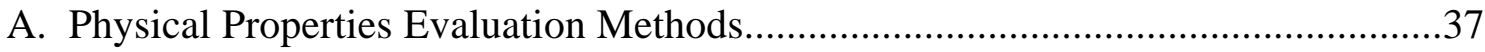

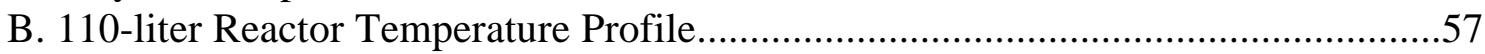

C. Silica-Based Diphonix Resin Manufacture Flowsheet................................................61 


\section{List of Tables}

Table 1. Resin Physical Properties Evaluation...........................................................6

Table 2. Comparison of Drying Methods for Activating Silica Gel.............................10

Table 3. Optimization Studies - Trimethoxyvinylsilane and Triethylamine

Quantities in the Synthesis of Vinyl Modified Silica Gel........................11

Table 4. Effect of Reaction Temperature on the Synthesis of Vinyl

Modified Silica Gel

Table 5. Effect of Reaction Time on the Synthesis of Vinyl Modified

Silica Gel

Table 6. Effect of 1,6-Hexanediol Diacrylate and BPO Levels

on the Grafting Reaction Yield.

Table 7. Effect of VDPE Incorporation with Varying Levels of

1,6-Hexanediol Diacrylate in Grafting Reaction

Table 8. Effect of Acrylic Acid on Grafting Reaction Yield

Table 9. Effect of Reaction Temperature and Time in Hydrolysis Reaction.................20

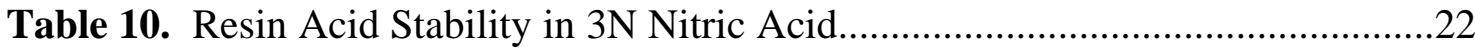

Table 11. Resin Thermal Stability Study at $65^{\circ} \mathrm{C}$ for 1 hour......................................22

Table 12. Resin Physical Properties Evaluation - Expected vs. Achieved.....................27

Table 13. Vinyl Group Content of Modified Silica Gel - Scale-up Comparison...........29

Table 14. Physical Property Comparison of Silica-based Diphonix

Prepared at Different Scales

Table 15. Comparison of Fe(III) Loading Capacities in 3 N Nitric Acid,

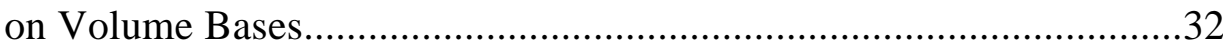

Table 16. Cost Calculation for Silica-Based Diphonix in 110-liter Reactor....................33

Table 17. Cost Calculation for Polystyrene-Based Diphonix in 110-liter Reactor.........34

Table 18. Comparison of Required Success Criteria vs Success Achieved......................35 


\section{List of Figures}

\section{Page}

Figure 1. Diphonix Resin Polymer Matrix...................................................... 2

Figure 2. The Originally Proposed Synthesis Route..............................................14

Figure 3. The Newly Developed Synthesis Route...............................................16

Figure 4. The $\mathrm{D}_{\mathrm{w}}$ of $\mathrm{Fe}(\mathrm{III})$ in Various Concentrations of Nitric Acid.....................23

Figure 5. Kinetics of Fe(III) Uptake in 3N Nitric Acid....................................25

Figure 6. Comparison of Fe(III) Breakthrough Curves and Salt Effect....................26

Figure 7. Temperature Record of Grafting Reaction in 110-liter Reactor..................30

Figure 8. Comparison of Fe(III) Breakthrough Curves........................................31 


\section{List of Acronyms}

\section{Acronym}

$\begin{array}{ll}\text { ACN } & \text { acrylonitrile } \\ \text { BPO } & \text { Benzyl Peroxide } \\ \text { Ci } & \text { curie } \\ \text { Cl } & \text { chloride } \\ \text { cm } & \text { centimeter } \\ \text { CRADA } & \text { Cooperative Research and Development Agreement } \\ \text { DI } & \text { deionized (water) } \\ \text { DOE } & \text { Department of Energy } \\ \text { DVB } & \text { divinylbenzene } \\ \text { Dw } & \text { weight distribution ratio } \\ \text { EDTA } & \text { ethylene diamine tetraamine, a chelator } \\ \text { EPA } & \text { Environmental Protection Agency } \\ \text { fcV } & \text { free column volume } \\ \text { GRAS } & \text { generally recognized as safe } \\ \text { HLW } & \text { high level waste } \\ \text { i.d. } & \text { inner diameter } \\ \text { LLW } & \text { low level waste } \\ \text { MW } & \text { molecular weight } \\ \text { NCAW } & \text { a Hanford waste form } \\ \text { NRC } & \text { Nuclear Regulatory Commission } \\ \text { PCB } & \text { polychlorinated biphenyl } \\ \text { SST } & \text { single shelled tank (Hanford) } \\ \text { SY-101 } & \text { a Hanford tank } \\ \text { UT } & \text { University of Tennessee } \\ \text { VBC } & \text { vinylbenzyl chloride } \\ \text { VDPE } & \text { vinylidene diphosphonate }\end{array}$




\section{Executive Summary}

Eichrom's highly successful Diphonix ${ }^{\circledR}$ resin resembles a conventional ion exchange resin in its use of sulfonic acid ligands on a styrene-divinylbenzene matrix. Diphonix resin exhibits rapid exchange kinetics that allow economical operation of ion exchange systems. Unlike conventional resins, Diphonix resin contains chelating ligands that are diphosphonic acid groups that recognize and remove the targeted metals and reject the more common elements such as sodium, calcium and magnesium. This latter property makes Diphonix ideal for many industrial scale applications, including those involving waste treatment. For treatment of low-level, transuranic (TRU) and high-level radioactive wastes, Diphonix's polystyrene backbone hinders its application due to radiolytic stability of the carbon-hydrogen bonds and lack of compatibility with expected vitrification schemes. Polystyrene-based Diphonix is approximately 60\% carbonhydrogen.

In response to an identified need within the Department of Energy for a resin with the positive attributes of Diphonix that also exhibits greater radiolytic stability and final waste form compatibility, Eichrom has successfully developed a new, silica-based resin version of Diphonix. Target application for this new resin is for use in environmental restoration and waste management situations involving the processing of low-level, transuranic and high-level radioactive wastes. The resin can also be used for processing liquid mixed waste (waste that contains low level radioactivity and hazardous constituents) including mixed wastes contaminated with organic compounds. Silica-based Diphonix is only $10 \%$ carbon-hydrogen, with the bulk of the matrix silica.

Advantages of this new resin are:

- $\quad$ increased radiolytic stability of the silica-based resin relative to its polystyrene-based counterpart

- $\quad$ a resultant waste form that is amenable to disposal without additional treatment or that can be vitrified more readily than the conventional ion exchange resins

- better silica matrix stability at highly basic $\mathrm{pH}(\mathrm{pH}$ above 11) than other silica ion exchangers

- $\quad$ performance improvements with waste streams containing organic compounds (> 1\%)

The successes of this development effort are summarized as follows:

- An economic three step synthesis route has been demonstrated as opposed a proposed four step route 
- Demonstrated stability in both acid and thermal stability tests

- Uptake for metal ions one order of magnitude greater than required

- $\quad$ Better kinetic and breakthrough performance than the polystyrene-based counterpart

- $\quad$ Comparable loading capacity compared to the polystyrene-based counterpart

- $\quad$ Successful demonstration at the 110-liter pilot reactor scale

- $\quad$ Comparable cost for manufacturing at the 110-liter compared to the polystyrene-based counterpart

Based on observations made during this phase of the effort, recommendations are made for additional studies to be accomplished as part of the second phase of the program. These additional studies can be performed within the scope and budget of the second phase.

The base phase of the program was successfully completed within the allotted 13month time frame and was concluded approximately twenty percent under budget. Details of the effort are presented in this report. 


\section{Introduction}

Conventional sulfonic acid and amine type ion exchange resins are widely used in many commercial applications including the softening or deionizing of water, treatment of industrial wastewater and the production and recovery of metals. However, these resins have limited use in specialized applications such as the preconcentration and removal of trace metals for the purpose of analysis, the treatment of industrial waste water to the parts per billion level, and the removal of radionuclides from highly acidic waste streams. Specialized applications require more selective ion exchange resins that target one or more metal ions so their capacity is not exhausted removing the more common cations (sodium, magnesium, calcium) or anions (chlorides, sulfates, nitrates). In response to the need for greater selectivity, a class of resins, called chelating ion exchange resins, was developed and commercialized. Chelating resins provide a dramatic improvement in ion selectivity relative to traditional ion exchange resins but still suffer from two distinct drawbacks: slow metal uptake kinetics and a limited operating $\mathrm{pH}$ range. Slow reaction kinetics result in the underutilization of resin capacity and premature ion breakthrough. These, in turn, lead to higher capital and operating costs for the systems in which the chelating resins are used. The inability of chelating resins to remove target metal ions selectively from highly acidic solutions prevents their effective use with waste streams such as acidic nuclear waste, acid mine drainage and metal processing streams.

The shortcomings of chelating reins have been addressed by the development of a new class of ion exchange resins called dual mechanism bifunctional polymers (DMBPs). Like conventional ion exchange resins, DMBPs use hydrophilic cation exchange ligands that have rapid uptake kinetics; and like chelating resins, DMBPs use chelating ligands to achieve selectivity for one or more metals. By combining hydrophilicity and selectivity, DMBPs overcome the limitations of conventional resins (selectivity) and of chelating resins (uptake kinetics). The result is a resin that quickly recognizes and removes targeted metals from waste, remediation and process streams.

Eichrom's Diphonix resin represents the first DMBP to be widely released as a commercial product. Diphonix resin was developed by researchers at the DOE's Argonne National Laboratory and at the University of Tennessee. Eichrom licensed the technology and has successfully commercialized it in applications as diverse as metallurgical processing, mixed waste treatment, semiconductor manufacturing and electric power plant water treatment.

Eichrom's Diphonix resin, illustrated in Figure 1, resembles a conventional ion exchange resin in its use of sulfonic acid ligands on a styrene-divinylbenzene matrix. Therefore, Diphonix resin exhibits the rapid exchange kinetics that allow economical operation of ion exchange systems. Unlike conventional resins, Diphonix resin contains chelating ligands that reject common elements and limit the resin's uptake to targeted metal ions. These chelating ligands are gem-diphosphonic acid groups that recognize and remove the targeted metals and reject the more common elements such as sodium, calcium and magnesium. Moreover, systems using Diphonix resin look and operate no differently 
than do systems using conventional ion exchange resins. No specialized equipment or operator training is required and regenerating the resin is similar to the regeneration of other ion exchange resins.

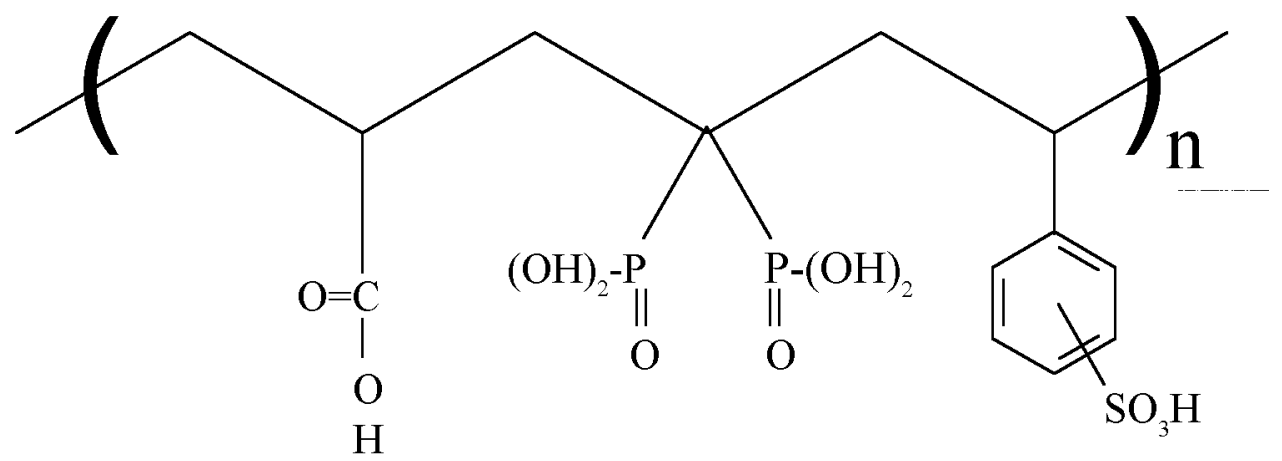

Figure 1: Diphonix Resin Polymer Matrix

Diphonix resin also addresses another limitation of chelating resins: operation at low $\mathrm{pH}$ ranges. The gem-diphosphonic acid ligands of the Diphonix resin tend to form protonated metal complexes. As a result, the resin retains its selectivity and capacity for metals under conditions that are typically too acidic for appreciable metal complexation by conventional and chelating ion exchange resins.

Physical and chemical properties of Diphonix resin are shown below:

Ionic Form:

Density:

Moisture Content:

Particle Size Ranges:

Capacity:
Hydrogen

Ranges from 1.05 to $1.11 \mathrm{~g} / \mathrm{mL}$ depending on mesh size.

Varies with cross-linkage specified. Typical value is $70 \%$ for $5 \%$ divinylbenzene crosslinked beads.

Available in 20-50 mesh, 50-100 mesh and 100-200 mesh.

Hydrogen capacity $=5-6 \mathrm{mmol} / \mathrm{g}$ Phosphorus capacity $\approx 0.7$ millequivalents per gram of dry resin 
Capacity in the above table refers to the maximum number of phosphorus sites (expressed as milliequivalents $\mathrm{P}$ per gram of dry resin) available for binding metal ions and is called total theoretical capacity.

Currently, Diphonix resin is synthesized by a patented process involving copolymerization of a tetraalkylvinylidene diphosphonate with styrene, divinylbenzene, and acrylonitrile followed by sulfonation with concentrated sulfuric acid. Determining a method for effectively copolymerizing the vinylidene diphosphonate ester was a major achievement because of the steric hindrance imposed on the vinylidene group by the diphosphonate group. This difficulty was overcome by using another relatively small monomer, acrylonitrile, as a carrier to induce polymerization of the vinylidene diphosphonate.

A new, silica-based resin functionalized with diphosphonic acid ligands can be used in a number of environmental restoration and waste management situations involving the processing of low-level, transuranic (TRU) and high-level radioactive wastes. It can also be used for processing liquid mixed waste (waste that contains low level radioactivity and hazardous constituents) including mixed wastes contaminated with organic compounds. The advantages expected of the new resin technology are:

- $\quad$ increased radiolytic stability of the silica-based resin relative to its polystyrene-based counterpart (Diphonix resin)

- $\quad$ a resultant waste form that is amenable to disposal without additional treatment or that can be vitrified more readily than the conventional ion exchange resins

- $\quad$ better silica matrix stability at highly basic $\mathrm{pH}(\mathrm{pH}$ above 11) than other silica ion exchangers

- $\quad$ performance improvements with waste streams containing organic compounds $(>1 \%)$

Radiolytic Stability: A pressing challenge posed by wastes of the DOE complex is radioactivity and the concomitant need for radiolytically stable treatment technologies. Radiation damage to polystyrene-based ion exchange resins is caused by the rupture of the carbon-carbon bonds in the resins' crosslinkages leading to resin degradation and loss of metal uptake capacity. Generally, cation exchangers have higher radiolytic stability than anion exchangers and highly cross-linked exchangers are more stable than those with a low degree of cross-linkages. A silica-based support, in contrast, consists of silicon and oxygen bonded together in a rigid, highly porous matrix. The silicon-oxygen bonds are much stronger than the carbon-carbon bonds and are much less susceptible to radiation degradation. Therefore, a silica support is expected to be more stable in radioactive conditions. 
Vitrification: Vitrification is a thermal process that chemically incorporates or encapsulates hazardous and radioactive contaminants into a glass or glass-like substance. In the vitrification process, the inorganic contaminants are melted or dissolved into molten liquid that when cooled forms a glass product that chemically incorporates or encapsulates the contaminants. Vitrification also destroys organic contaminants. The composition of the waste stream to be vitrified is important. The waste must contain a favorable proportion of glass forming compounds (silicon, aluminum and iron oxides) or these materials must be added to obtain the appropriate level. Since a silica-based Diphonix resin will be essentially $100 \%$ silicon dioxide compared a polystyrene-based exchanger which would contain no silicon dioxide material, less glass-forming material will be required for vitrification. Therefore, a silica-based Diphonix ion exchange resin should be more readily vitrifiable than polystyrene resins, and, in fact, could itself be used as a glassforming additive.

pH Characteristics: It is known that silica-based material will normally dissolve under highly basic conditions ( $\mathrm{pH}$ above 11 ). However, preliminary laboratory studies have shown that silica-based Diphonix resin is not subject to dissolution in highly basic conditions and therefore maintains it metal uptake capacity. The reason for matrix stability under highly basic conditions is the chemical modification of the silica surface "seals off" any exposed silanol sites, preventing basic ions from dissolving the silica matrix (silicon-oxygen bonds). Therefore, silica-based Diphonix resin is expected to be more effective at high $\mathrm{pH}(>11)$ than other silica-based ion exchangers.

Organic Tolerance: Many of the waste streams generated within the DOE combine actinides, other radionuclides and organic contaminants under highly acidic or highly basic conditions. This combination of contaminants eliminates the effectiveness of most ion exchangers and significantly restricts treatment options. Polystyrene-based Diphonix resin, like all ion exchange resins with organic matrices, is subject to organic fouling which occurs when organic contaminants form a coating over the polystyrenebased resin bead. A silica-based Diphonix resin is less likely to foul because the inorganic silica-based matrix will not be as easily coated with an organic contaminant. Because it resists fouling, it is likely to more effective in treating the organic-containing wastes of the DOE.

The major technical challenge of synthesizing silica-based Diphonix resin is incorporation of diphosphonic acid groups onto silica particles in quantities that provide metal loading capacity, kinetics and acid stability comparable to the polystyrene-based Diphonix resin. The synthesis of polystyrene-based Diphonix resin as described above is achieved in a two-step process that consists of (i) a copolymerization step in which the diphosphonic acid groups are incorporated throughout the organic matrix and (ii) a sulfonation step that adds the sulfonic acid group and hydrolyzes the phosphate esters. The synthesis of silica-based Diphonix resin will require that the diphosphonic acid groups be chemically bonded onto the surfaces of the silica particles in a multi-step process. The silica particles are highly porous and include both micro and macro pores in a rigid solid matrix of silicon dioxide that contains little or no moisture. The silica matrix is 
functionalized by attaching diphosphonic acid groups onto the silanol sites contained on the macroporous surface. Silanol sites in the silica micropores are not functionalized and are rendered inaccessible by the synthesis process. Because of silica's high porosity, the kinetics are expected to be comparable to those of the polystyrene-based Diphonix resin.

\section{Objectives}

The objective of this work is to synthesize commercial quantities of a silica-based ion exchange resin with the same or better metal ion selectivity, metal uptake kinetics and acid stability as the commercially available polystyrene-based Diphonix ion exchange resin.

Specific tasks were be performed during this effort to obtain the stated objectives. These tasks are identified below:

- Design and Develop a Silica Gel Based Resin Functionalized with Diphosphonate Ligands

A multi-step process is involved in meeting this objective. First, the silica gel must be functionalized. This requires the production of resin with $>90 \%$ coverage of available silanol sites. Second, ligands must be grafted onto the functionalized silica. This step requires a high level of grafting (80-90\%) that can be estimated by measuring the bromine number, chlorine elemental analysis, and a qualitative porosity evaluation made from standard porosity measurements. Next, the grafted silica material is reacted with the addition of diphosphonate ligands. The extent of phosphonate addition is determined by elemental phosphorus analysis of the resin. Lastly, the phosphonic ester groups must be hydrolyzed.

\section{- Resin Physical Properties Evaluation}

Product resins undergo a series of physical property tests which are described in Table 1.

- Scale-Up and Economic Analysis

Once a resin has been produced that meets the evaluation criteria outlined in Table 1 , scale-up of the synthesis scheme needs to be demonstrated. Scale-up progresses from a laboratory scale 2-liter reactor through 5-liter and 22-liter reactors to the 110-liter reactor. Process economics are studied at each step. The final objective is to produce silica-based Diphonix resin at the 110-liter scale with a cost comparable to the cost of polystyrenebased Diphonix resin at the 110-liter scale. 


\section{Table 1. Resin Physical Properties Evaluation}

\section{$\underline{\text { Test }}$}

Visual Examination

Phosphorus content

Acid capacity

Thermal stability (acid capacity after heating at $65^{\circ} \mathrm{C}$ for one hour)

Fe(III) uptake

Stability in $3 \mathrm{M} \mathrm{HNO}_{3}$

Percent Solids

\section{$\underline{\text { Purpose }}$}

Look for evidence of bead structure problems

Measurement of the ligand sites available for metal ion uptake

Determine the number of cation sites available for exchange

Determine loss of cation sites when resin is heated

Test availability of ligands for metal ion uptake (ferric is a good predictor of performance with actinides)

Test bead stability in strong acid

Determine the dry weight of the resin

\section{$\underline{\text { Expected Result }}$}

No more than 5 abnormal beads per 100

$1.4 \mathrm{mmol} /$ gram dry resin, minimum

$2 \mathrm{X}$ phosphorus content minimum

Less than $5 \%$ reduction

Distribution coefficient greater than $10^{3}$ at 30 minutes contact time

No bead structure problems; no signs of silica matrix dissolution

Higher solids content compared to poly-styrene based Diphonix $(\sim 30 \%)$ resin

\section{Experimental - Laboratory Scale Synthesis}

\section{Synthesis of the vinyl modified silica gel (Silica-VS)}

In a three-neck round bottom flask equipped with thermometer, condenser tube and mechanical stirrer, the dried silica gel (Davisil, Grade 645, 60-100 mesh size, $300 \mathrm{~m}^{2} / \mathrm{g}$ surface area, $150 \AA, 1.15 \mathrm{~cm}^{3} / \mathrm{g}$ pore volume, from W. R. Grace Co.) is suspended in toluene and triethylamine (dried using molecular sieve overnight) with stirring at room temperature for 30 minutes and subsequently reacted with trimethoxyvinylsilane at temperature for 6 to 12 hours. The modified silica gel is then washed three times with 100 $\mathrm{mL}$ of methanol and dried on rotary evaporator at elevated temperature. The vinyl group content is determined by bromination method.

\section{Synthesis of tetraisopropylvinylidene diphosphonate (VDPE) grafted silica gel (Silica-g-VDPE)}

The vinyl modified silica gel, 40.0 grams, is blended with a premixed monomer solution containing VDPE (vinylidene diphosphonate), acrylic acid, 1,6-hexanediol diacrylate (cross-linking agent), BPO (benzoyl peroxide, polymerization initiator), and a low boiling point solvent, such as acetone, to make a slurry. The solvent is stripped continuously on a rotary evaporator until $90 \%$ of the solvent is removed. The monomer impregnated silica is then heated in $160 \mathrm{~mL}$ of $25 \% \mathrm{NaCl}_{(\mathrm{aq})}$ at $65^{\circ} \mathrm{C}$ for 1 hour and then 
$75^{\circ} \mathrm{C}$ for 16 hours. The $\mathrm{NaCl}$ solution prevents monomers from leaching into aqueous phase. The product is eluted with 2 bed volume of acetone in a column to remove any ungrafted materials followed by drying on a rotary evaporator. The yield of the phosphonate grafting reaction is determined by both mass balance, based upon the total quantity of monomers used for grafting, and the phosphorus elemental analysis of the grafted resin.

\section{Hydrolysis of VDPE grafted silica gel}

The grafted silica gel, 50 grams, is hydrolyzed in $200 \mathrm{~mL}$ of $3 \mathrm{~N} \mathrm{HCl}$ at $95^{\circ} \mathrm{C}$ for 3 hours. After cooling to room temperature, the product is rinsed in a column with 1.5 bed volumes of isopropyl alcohol, 1.5 bed volumes of acetone, and finally 3 bed volumes of DI water. The hydrolyzed resin is characterized by percent solids, acid capacity (meq/g) and phosphorus capacity (meq/g).

\section{Physical Properties Analysis}

Vinyl Group Capacity: Approximately $3.5 \mathrm{~g}$ of Silica-VS is mixed with $25 \mathrm{~mL}$ acetic acid, $25 \mathrm{~mL} 0.2 \mathrm{~N}$ standardized bromine solution and $25 \mathrm{~mL} 10 \%$ sulfuric acid in a $500 \mathrm{~mL}$ bromination bottle under a pressure $1 / 3 \mathrm{~atm}$ or lower. The bottle is then shield from light and agitated for 30 minutes. After mixing with $25 \mathrm{~mL}$ of $1.0 \mathrm{~N} \mathrm{KI}$ solution, the liberated iodine is titrated with standardized thiosulfate solution to the blue starch end point.

Percent Solids Determination (Moisture Content): The resin is air dried on Büchner funnel with a course filter paper at $660 \mathrm{~mm} \mathrm{Hg}$ for 5 minutes. Resin dried in this manner is referred to as air dried resin. An air dried sample weighed by analytical balance is heated at $110^{\circ} \mathrm{C}$ oven for 16 hours and then is allowed to cool in a desiccator prior to determination of the dry mass.

Acid Capacity: $1.0-1.5 \mathrm{~g}$ of air dried resin is agitated gently with $100 \mathrm{~mL}$ of standardized $0.10 \mathrm{~N} \mathrm{NaOH}$ for 15 minutes. The basic solution was quantitatively transferred to a $250 \mathrm{~mL}$ volumetric flask with filtering. A $50 \mathrm{~mL}$ aliquot of this solution was titrated with standardized $0.10 \mathrm{~N} \mathrm{H}_{2} \mathrm{SO}_{4}$.

Phosphorus elemental analysis: Approximately $25 \mathrm{mg}$ of oven dried resin was digested with $100 \mu \mathrm{L}$ of $1 \mathrm{M} \mathrm{CuSO}_{4(\text { aq) }}$ and $5 \mathrm{~mL}$ concentrated $\mathrm{H}_{2} \mathrm{SO}_{4}$ followed by another gentle heating with $50 \mathrm{~mL}$ of fresh $4 \% \mathrm{Na}_{2} \mathrm{~S}_{2} \mathrm{O}_{8 \text { (aq) }}$. After the solution is cooled, neutralized, and diluted to $100 \mathrm{~mL}$, a $25 \mathrm{~mL}$ aliquot is mixed with $10 \mathrm{~mL}$ of sodium vanadate solution. The mixture is diluted to $50 \mathrm{~mL}$ and allowed to develop for 30 minutes. The solution's absorbance was then measured at $470 \mathrm{~nm}$ on a Bausch and Lomb Spectronic 21 and the percent phosphorus determined from Beer's law plot using a series of $\mathrm{KH}_{2} \mathrm{PO}_{4}$ standards. 
Stability in 3N Nitric Acid: Approximately $10 \mathrm{~g}$ of air dried resin was mixed with $50 \mathrm{~mL}$ of $3 \mathrm{~N}$ nitric acid and agitated for 3 and 7 days. The resin was then conditioned in a column with DI water until the eluant was near neutral $\mathrm{pH}$. The percent solid, acid capacity and phosphorus content for the resin were determined again to measure the stability in acid.

$\mathrm{D}_{\mathrm{w}}$ Measurement of $\mathrm{Fe}(\mathrm{III})$ Uptake: The sorption of the ${ }^{59} \mathrm{Fe}$ isotope at trace level concentration is measured. Dry weight distribution ratio $D_{w}$, is calculated as

$$
D_{\mathrm{w}}=\left\{\left(\mathrm{A}_{0}-\mathrm{A}_{\mathrm{f}}\right) / \mathrm{W}\right\} /\left(\mathrm{A}_{\mathrm{f}} / \mathrm{V}\right)
$$

where: $\mathrm{A}_{0}=$ aqueous phase activity before equilibration

$\mathrm{A}_{\mathrm{f}}=$ aqueous phase activity after equilibration

$\mathrm{W}=$ weight of dry resin in grams

$\mathrm{V}=$ aqueous phase volume in $\mathrm{mL}$

Kinetic of $\mathrm{Fe}$ (III) Uptake in 3N Nitric Acid: We soaked one gram of air dried resin with $25 \mathrm{~mL}$ of $3 \mathrm{~N}$ nitric acid in a $250 \mathrm{~mL}$ plastic bottle for 15 minutes, and then added $25 \mathrm{~mL}$ of $1000 \mathrm{ppm} \mathrm{Fe(III)/3N} \mathrm{nitric} \mathrm{acid} \mathrm{solution.} \mathrm{We} \mathrm{agitated} \mathrm{the} \mathrm{bottle} \mathrm{and}$ measured the concentration of $\mathrm{Fe}(\mathrm{III})$ at each time point by taking $100 \mu \mathrm{L}$ of sample from the mixture. We obtained a plot of percent absorption as a function of time.

Breakthrough Curve of Fe(III) Uptake in 3N Nitric Acid: The studies were done in a glass column suitable for holding $25 \mathrm{~mL}$ of solution. The $10 \mathrm{~mL}$ of resin was measured out in deionized water using a graduated cylinder. The resin was then transferred to the column and a plunger was added to minimize the head space between the top of the resin bed and the inlet for the solution. The resin was pretreated with $5 \mathrm{BV}$ $(1 \mathrm{BV}=10 \mathrm{~mL})$ of solution matched to the feed solution without Fe(III) present. A 200 ppm Fe(III) feed solution was then run over the column at a measured flow rate and collected in $40 \mathrm{~mL}$ samples. All samples were diluted with deionized water and analyzed by flame AA spectroscopy.

\section{Results and Discussion of Laboratory Scale Synthesis}

\section{Synthesis of vinyl modified silica gel}

The preparation of vinyl modified silica gel has been described in numerous literature references. Prior to modification, the silica gel is usually activated in an oven at an elevated temperature to remove any hydrogen bonded water. Performing this pretreatment technique in the large quantities needed for scale-up is difficult. The dried resin may reabsorb moisture from atmosphere during the transfer to the reaction tank. An alternative technique, azeotropic distillation, was chosen to replace the traditional oven drying method. In the azeotrope process, the silica gel is heated with toluene at reflux temperature in the reaction vessel until all of the water is removed as the toluene-water 
azeotrope from a Dean-Stark trap. Since toluene is the desired solvent for the vinyl modification reaction, the silica gel can then be directly used in the reaction vessel for the subsequent process. Moreover, the azeotrope dried silica gel remains in toluene and contact with moisture in atmosphere can be virtually eliminated. The results of the control experiment shown in Table 2 indicate that both drying methods remove equivalent amounts of water and yield modified silica gel with equivalent vinyl group capacities.

In most of the published articles on the subject, trichlorovinylsilane is reacted with silica gel in toluene in the presence of triethylamine to modify the surface of silica gel. Due to the safety consideration in scale up, and since trichlorovinylsilane is a highly corrosive and reactive chemical, trimethoxyvinylsilane was substituted in the current work. The reaction was optimized with varying concentrations of trimethoxyvinylsilane with and without the use of triethylamine as a catalyst for the modification reaction. The results presented in Table 3 indicate that triethylamine has a catalytic effect on this reaction. A saturation level vinyl group content in the range of 0.85 and $0.90 \mathrm{meq} / \mathrm{g}$ is achieved when using more than $4 \mu \mathrm{mole} / \mathrm{m}^{2}$ (silica gel surface area) of triethylamine and trimethoxyvinylsilane. The influence of reaction temperature and time on the yield was also studied with the quantity of reagents noted above. The results of these tests are presented in Tables 4 and 5. The data indicates that running the reaction at $70^{\circ} \mathrm{C}$ for 6 hours (vs. reflux temperatures for 12 hours as indicated in the literature) is sufficient to produce product with vinyl group content in the saturation range. The scale-up specification for minimum vinyl group content is $0.81 \mathrm{meq} / \mathrm{g}$ based upon $90 \%$ of vinyl group capacity of the highest level observed during the laboratory study. Thus, the optimal conditions determined for the vinyl modification reaction are as follows:

$\begin{array}{ll}\text { Surface Activation: } & \text { Azeotrope } \\ \text { Solvent: } & 3 \mathrm{~mL} \text { of toluene per g of silica gel } \\ \text { Quantity of Triethylamine: } & 4 \mu \text { mole } / \mathrm{m}^{2}(122.8 \mathrm{mg} / \mathrm{g} \text { of silica gel }) \\ \text { Selection of Silane: } & \text { Trimethoxyvinylsilane (TMVS) } \\ \text { Quantity of TMVS: } & 4 \mu \mathrm{mole} / \mathrm{m}^{2}(181.7 \mathrm{mg} / \mathrm{g} \text { of silica gel }) \\ \text { Reaction Temperature: } & 70^{\circ} \mathrm{C} \\ \text { Reaction Time: } & 6 \text { hours }\end{array}$

\section{Synthesis of VBC grafted silica gel}

In the originally proposed synthetic route, the preparation of silica-based Diphonix resin involved four separate reaction steps. These steps are depicted in Figure 2. Since this process posed several technical difficulties, we concluded that it would be almost impossible to develop a commercially and economically viable process via this route. As an example, the grafting of vinylbenzyl chloride (VBC) onto the vinyl modified silica gel in toluene gives a product with a yield less than $15 \%$ based on VBC usage. More than $85 \%$ of $\mathrm{VBC}$ used for this grafting reaction is homopolymerized in the solution as a side product. Since VBC is expensive, the loss of up to $85 \%$ of $\mathrm{VBC}$ in the grafting reaction has a potentially significant influence on the cost for the product. Moreover, any VBC homopolymer would need to be removed prior to subsequent processing. This would 
Table 2: Comparison of Drying Methods for Activating Silica Gel

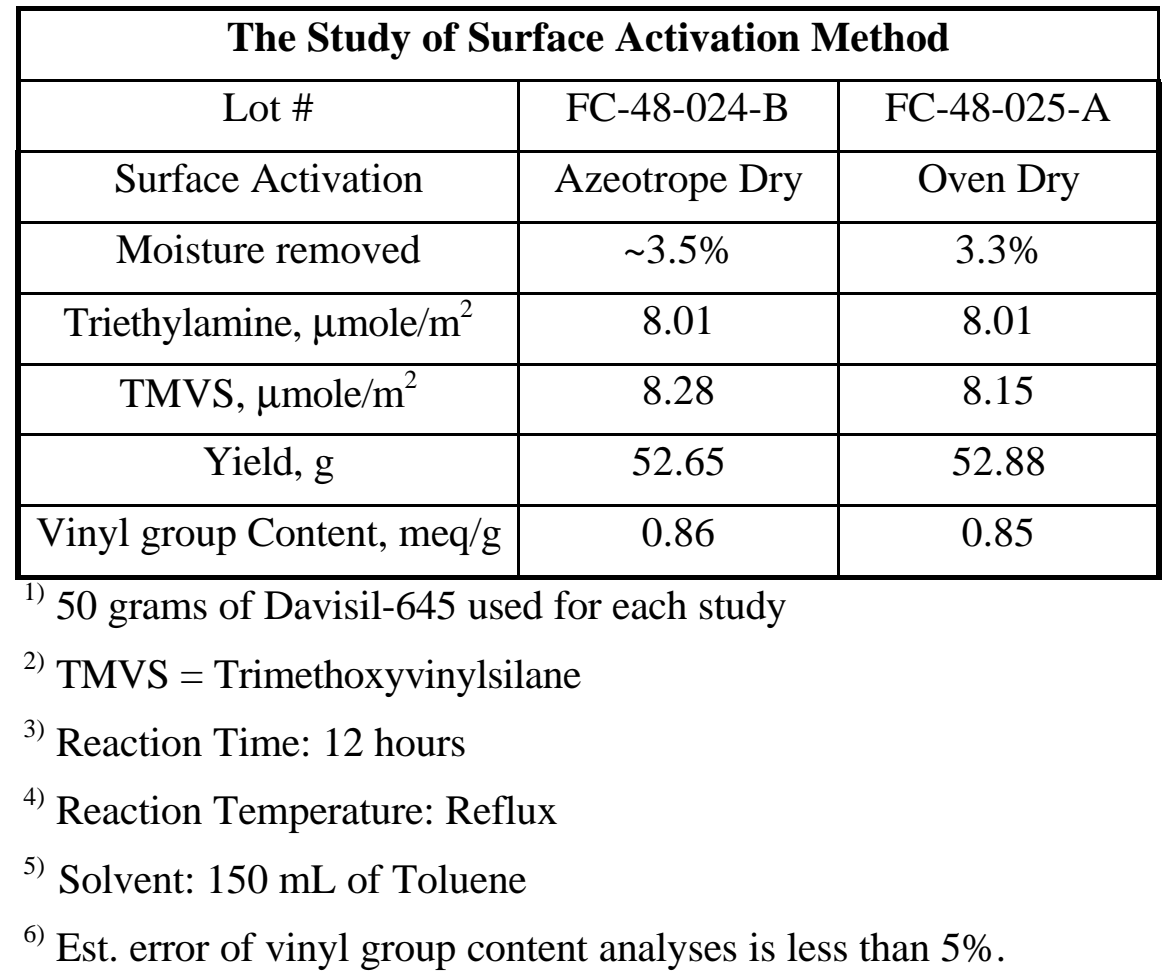


Table 3: Optimization Studies - Trimethoxyvinylsilane and Triethylamine Quantities in the Synthesis of Vinyl Modified Silica Gel

\begin{tabular}{|l|c|c|c|c|c|c|}
\hline Studies without triethylamine catalyst \\
\hline Batch \# & & FC-48-018-A & FC-48-024-A & & FC-48-028-A & FC-48-027-A \\
\hline TMVS, $\mu$ mole/m ${ }^{2}$ & & 16.8 & 8.31 & & 4.03 & 2.26 \\
\hline Yield, g & & 52.37 & 52.36 & & 51.83 & 51.31 \\
\hline Vinyl group Content, meq/g & & 0.81 & 0.8 & & 0.77 & 0.69 \\
\hline
\end{tabular}

\begin{tabular}{|l|c|c|c|c|c|c|}
\hline Studies with added of triethylamine catalyst \\
\hline Batch $\#$ & FC-48-019-B & FC-48-019-A & FC-48-025-A & FC-48-025-B & FC-48-028-B & FC-48-027-B \\
\hline TMVS, $\mu$ mole $/ \mathrm{m}^{2}$ & 17.18 & 16.84 & 8.15 & 5.40 & 4.31 & 2.80 \\
\hline Triethylamine, $\mu \mathrm{mole} / \mathrm{m}^{2}$ & 12.02 & 8.01 & 8.01 & 4.81 & 4.00 & 2.40 \\
\hline Yield, g & 52.42 & 52.59 & 52.88 & 52.56 & 52.69 & 51.63 \\
\hline Vinyl group Content, meq/g & 0.90 & 0.88 & 0.85 & 0.86 & 0.87 & 0.76 \\
\hline
\end{tabular}

1) 50 grams of Davisil-645 used for each study

2) TMVS = Trimethoxyvinyl silane

3) Reaction Time: 12 hours

4) Reaction Temperature: Reflux

5) Solvent: $150 \mathrm{~mL}$ of Toluene

6) Est. error of vinyl group content analyses is less than $5 \%$. 
Table 4: Effect of Reaction Temperature on the Synthesis of Vinyl Modified Silica Gel

\begin{tabular}{|l|c|c|}
\hline \multicolumn{3}{|l|}{ Studies without triethylamine catalyst } \\
\hline Batch \# & FC-48-028-A & FC-48-032-A \\
\hline Reaction Temperature & Reflux & $70^{\circ} \mathrm{C}$ \\
\hline TMVS, $\mu$ mole & 4.03 & 3.97 \\
\hline Yield, g & 51.83 & 51.92 \\
\hline Vinyl group Content, meq/g & 0.77 & 0.73 \\
\hline
\end{tabular}

\begin{tabular}{|l|c|c|}
\hline \multicolumn{4}{|l|}{ Studies with added triethylamine catalyst } \\
\hline Batch $\#$ & FC-48-028-B & FC-48-032-B \\
\hline Reaction Temperature & Reflux & $70^{\circ} \mathrm{C}$ \\
\hline TMVS, $\mu$ mole $/ \mathrm{m}^{2}$ & 4 & 4 \\
\hline Triethylamine, $\mu \mathrm{mole} / \mathrm{m}^{2}$ & 4.31 & 3.97 \\
\hline Yield, g & 52.69 & 52.49 \\
\hline Vinyl group Content, meq/g & 0.87 & 0.89 \\
\hline
\end{tabular}

1) 50 grams of Davisil-645 used for each study

2) TMVS=Trimethoxyvinyl silane

3) Reaction Time: 12 hours

4) Solvent: $150 \mathrm{~mL}$ of Toluene

${ }^{5)}$ Est. error of vinyl group content analyses is less than $5 \%$. 
Table 5: Effect of Reaction Time on the Synthesis of Vinyl Modified Silica Gel

\begin{tabular}{|c|c|c|}
\hline Batch \# & FC-48-032-B & FC-48-038 \\
\hline Reaction Time & 12 hours & 6 hours \\
\hline TMVS, $\mu \mathrm{mole} / \mathrm{m}^{2}$ & 4 & 4 \\
\hline Triethylamine, $\mu \mathrm{mole} / \mathrm{m}^{2}$ & 3.97 & 4.03 \\
\hline Yield, g & 52.49 & 52.23 \\
\hline Vinyl group Content, meq/g & 0.89 & 0.85 \\
\hline \multicolumn{3}{|c|}{ 1) The reactions are studied in the presence of triethylamine } \\
\hline \multicolumn{3}{|c|}{ 2) 50 grams of Davisil-645 used for each study } \\
\hline \multicolumn{3}{|c|}{ 3) $\mathrm{TMVS}=$ Trimethoxyvinyl silane } \\
\hline \multicolumn{3}{|l|}{${ }^{4)}$ Reaction Temperature: $70^{\circ} \mathrm{C}$} \\
\hline \multicolumn{3}{|l|}{ 5) Solvent: $150 \mathrm{~mL}$ of Toluene } \\
\hline \multicolumn{3}{|c|}{${ }^{6)}$ Est. error of vinyl group content analyses is less than $5 \%$. } \\
\hline
\end{tabular}




\section{Figure 2: The Originally Proposed Synthetic Route}
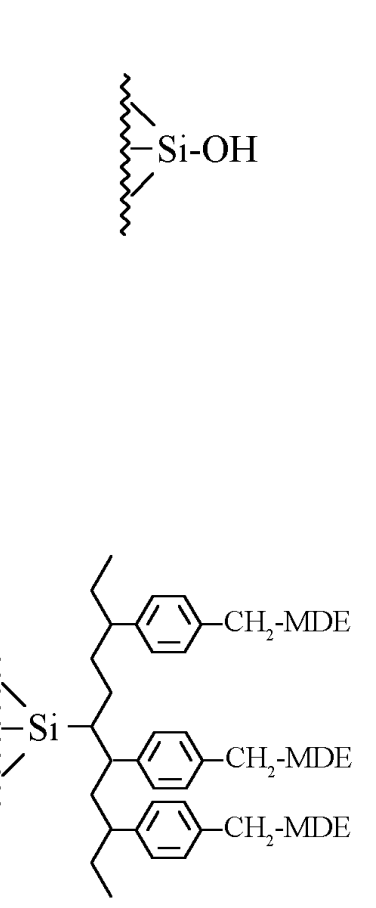

Tetraalkylmethylenediphosphonate $\mathrm{Na}($ or $\mathrm{NaH})$

Reflux, 24 hours

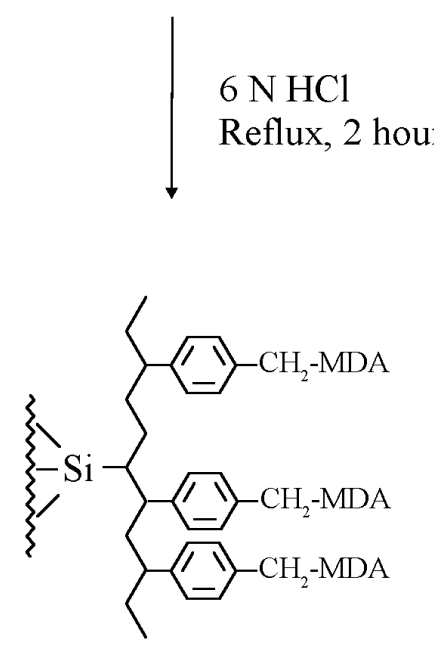

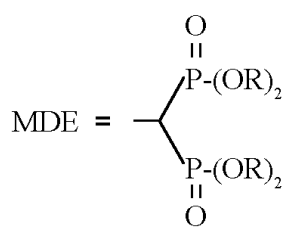

Trichlorovinylsilane

Reflux, 12 hours

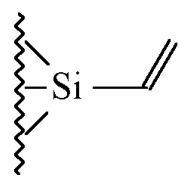

Vinylbenzylchloride AIBN in Toluene $80^{\circ} \mathrm{C}, 8$ hours

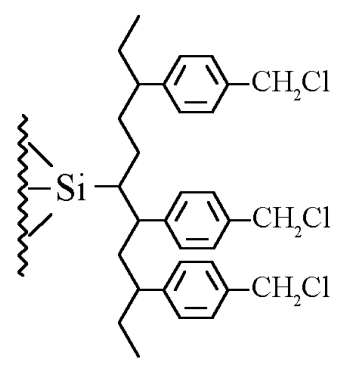

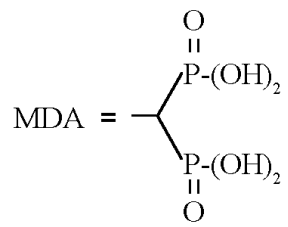


require an additional cleaning step, such as Soxhlet extraction which would contribute to the cost of the resin manufacturing. An alternative method to grafting VBC was investigated as part of our study. In this route, the $\mathrm{VBC}$ monomer is impregnated into the vinyl modified silica gel followed by heating at $80^{\circ} \mathrm{C}$ until dry. The quantity of VBC used for this route is significantly reduced and the grafting yield is improved. However, the yield from the addition of diphosphonate ester ligand to VBC is very low and the resin prepared from this technique exhibits very poor kinetic characteristics.

In order to resolve the technical difficulties with the originally proposed synthesis route, a new synthesis route containing only three reaction steps shown in Figure 3 was developed. In the new method, the vinyl modified silica gel is grafted directly with a monomer mixture solution which containing tetraisopropyl vinylidene diphosphonate (VDPE), acrylic acid, 1,6-hexanediol diacrylate and BPO. After the VDPE grafted silica gel is hydrolyzed, the product contains the same gem-diphosphonic acid group as the original silica-based Diphonix resin. The study of this new synthesis route is discussed in the following section.

\section{Synthesis of VDPE grafted silica gel}

The monomers used to graft the vinyl modified silica gel include tetraisopropyl vinylidenediphosphonate ester (VDPE), acrylic acid, 1,6-hexanediol diacrylate (crosslinking agent), and an initiator, BPO. Since VDPE shows a very slow polymerization character by itself due to the steric effect of two bulky phosphonate ester groups on the $\alpha$ carbon, acrylic acid is added to the system to increase the incorporation of VDPE in grafting reaction. Since the grafting technology used for this reaction may generate ungrafted linear copolymer as a side product, adding a small amount of cross-linking agent to the formula was expected to increase the probability of grafting the growing chains to the surface of silica gel. The effect of cross-linking on the kinetic performance of the final product is negligible since the cross-linking agent chosen, 1,6-hexanediol diacrylate, will be broken up to acrylic acid groups in the subsequent hydrolysis reaction.

During the grafting process, the monomers and initiator are first impregnated into the silica gel followed by heating the silica gel in a high salt aqueous solution at $75^{\circ} \mathrm{C}$. Since most of vinyl groups on the modified silica gel are bonded throughout the surface of the pores, the monomers would have a greater probability of being grafted if they are retained inside the silica gel pores. The aqueous phase used for this process provides both fluidity for mixing and also helps the heat transfer during the grafting reaction. The high level of salt in the aqueous solution used in the grafting process prevents the leaching of monomers to the aqueous phase.

The optimization of 1,6-hexanediol diacrylate and initiator levels was studied with 9.0 grams of VDPE and 4.25 grams of acrylic acid for each 20.0 grams of Silica-VS. The yield of the grafting reaction and the phosphorus content (Table 6) improve with the increase of both diacrylate and BPO; however, the phosphorus content starts leveling off when more than 0.5 grams of diacrylate and 0.75 grams of BPO are used. 


\section{Figure 3: The Newly Developed Synthesis Route}

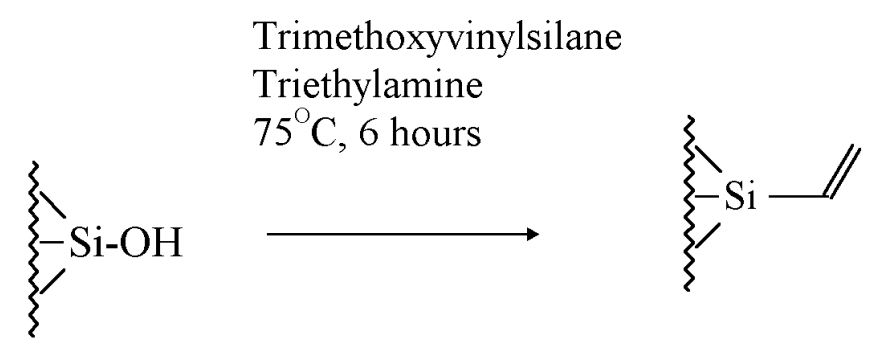

Tetraalkylvinylidene diphosphonate Acrylic acid Benzoyl peroxide $65^{\circ} \mathrm{C} / 1$ hours $75^{\circ} \mathrm{C} / 16$ hours
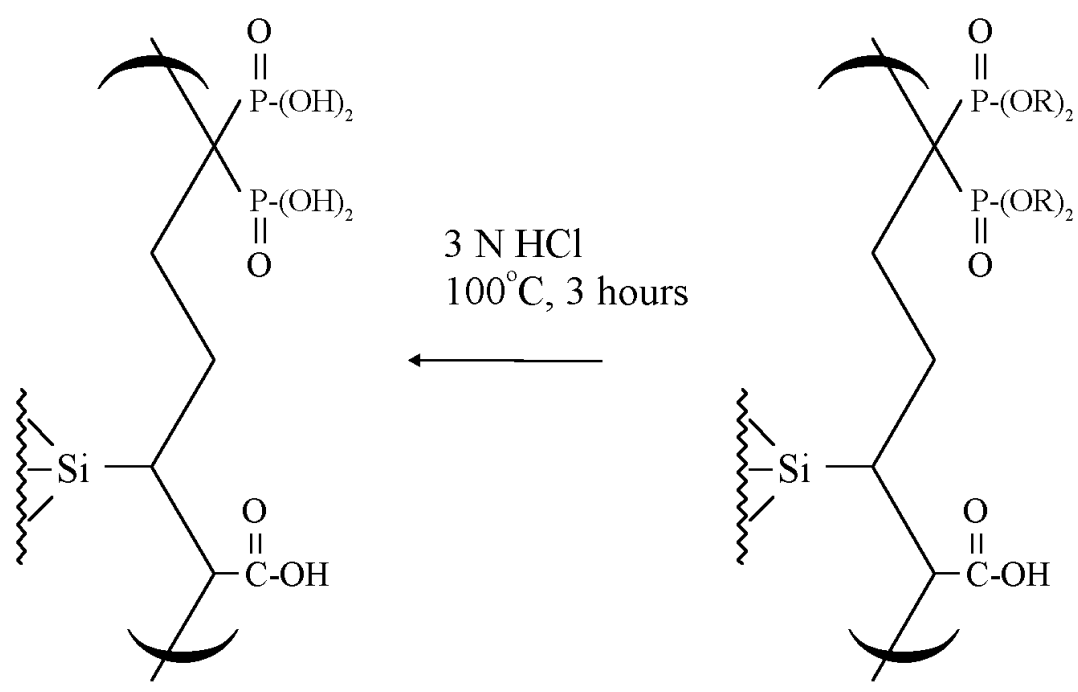
Table 6: Effect of 1,6-Hexanediol Diacrylate and BPO Levels on the Grafting Reaction Yield

\begin{tabular}{|c|c|c|c|c|}
\hline Grafting Yield & \multicolumn{4}{|c|}{ Quantity of 1,6-hexanediol diacrylate, $g$} \\
\hline $\mathrm{BPO}, \mathrm{g}$ & 0 & 0.25 & 0.5 & 0.75 \\
\hline 0.25 & $29.7 \%$ & $44.3 \%$ & $45.8 \%$ & $53.1 \%$ \\
\hline 0.5 & ------- & $52.8 \%$ & $58.6 \%$ & $66.0 \%$ \\
\hline 0.75 & $45.0 \%$ & $57.9 \%$ & $63.7 \%$ & $69.4 \%$ \\
\hline 1 & $40.0 \%$ & $58.2 \%$ & $67.8 \%$ & $71.5 \%$ \\
\hline $\begin{array}{c}\text { Phosphorus } \\
\text { Content } \\
\text { meq/g }\end{array}$ & \multicolumn{4}{|c|}{ Quantity of 1,6-hexanediol diacrylate, $g$} \\
\hline $\mathrm{BPO}, \mathrm{g}$ & 0 & 0.25 & 0.5 & 0.75 \\
\hline 0.25 & 0.44 & 0.56 & 0.59 & 0.65 \\
\hline 0.5 & ----- & 0.70 & 0.73 & 0.77 \\
\hline 0.75 & 0.62 & 0.67 & 0.78 & 0.73 \\
\hline 1 & 0.65 & 0.71 & 0.76 & 0.73 \\
\hline
\end{tabular}

\footnotetext{
${ }^{1)}$ For each study, $9.0 \mathrm{~g}$ of VDPE, $4.25 \mathrm{~g}$ of acrylic acid and $20.0 \mathrm{~g}$ of vinyl modified silica gel are used
}

${ }^{2)}$ Est. errors of phosphorus content analyses is less than 5\%. 
The quantity of VDPE used was studied at two levels, 7.0 and 9.0 grams, for each 20.0 grams of Silica-VS. The results in Table 7 shows that the phosphorus content of the grafted product increases with increasing VDPE level. However, further studies using more than 9.0 grams of VDPE were not performed due to economic considerations. VDPE is costly and we did not feel that any phosphorus content gain would offset the added cost. The influence of acrylic acid is explored with and without the presence of diacrylate (Table 8). Both cases show that increasing the quantity of acrylic acid can improve the total grafting yield but does not have a significant impact on the phosphorus content of the product resin. The results indicate that the phosphorus content of the product resin is a result of the VDPE quantity. Using excess quantity of acrylic acid only gives product with more acrylic acid units on the grafted polymer chains. The conditions used for the VDPE grafting reaction are summarized as follows:

VDPE:

Acrylic acid

1,6-Hexanediol diacrylate:

BPO:

Solvent for monomer solution:

$\mathrm{NaCl}(\mathrm{aq})$ for grafting reaction:

Grafting Temperature/Time:
$9.0 \mathrm{~g} / 20 \mathrm{~g}$ of Silica-VS

$4.25 \mathrm{~g} / 20 \mathrm{~g}$ of Silica-VS

$0.5 \mathrm{~g} / 20 \mathrm{~g}$ of Silica-VS

$0.75 \mathrm{~g} / 20 \mathrm{~g}$ of Silica-VS

$45 \mathrm{~mL}$ of acetone / $20 \mathrm{~g}$ of Silica-VS

$80 \mathrm{~mL}$ of $28 \% \mathrm{NaCl}_{(\mathrm{aq})} / 20 \mathrm{~g}$ of silica-VS

$65^{\circ} \mathrm{C}$ for $1 \mathrm{hr}, 75^{\circ} \mathrm{C}$ for $16 \mathrm{hr}$.

\section{Hydrolysis of VDPE grafted silica gel}

The hydrolysis of VDPE grafted silica gel in the final step of synthesis converts both gem-diphosphonate ester and diacrylate to gem-diphosphonic acid and acrylic acid respectively. The reaction temperature, reaction time, and the concentration of hydrochloric acid employed are listed in Table 9. Any change in the phosphorus content is due to the cleavage of the bonds between silica gel and the grafted polymer chains. The yield from hydrolysis is indicated by increases in acid content and decreases in percent solid. The acid content and percent solids can also be used as an indicator of the kinetic properties of the resin. The phosphorus content is an indicator of the loading capacity of the resin. The optimal conditions for hydrolysis should yield a product with high acid capacity while avoiding the loss of phosphorus content.

The conditions chosen for the optimized hydrolysis reaction are summarized as follows:

Acid Solution:

Reaction Temperature:

Reaction Time:
$80 \mathrm{~mL}$ of $3 \mathrm{~N} \mathrm{HCl} / 20$ gram of grafted resin $100^{\circ} \mathrm{C}$

3 hours

\section{Physical Property Evaluation}

Visual Examination: The product is examined visually with the aid of a microscope. There is not any evidence indicating structural problems such as clustering and gross deformities in the observation. The resins are also examined after the acid and 
Table 7: Effect of VDPE Incorporation with Varying Levels of 1,6-Hexanediol Diacrylate in Grafting Reaction

\begin{tabular}{|l|c|c|c|c|}
\hline Lot \# & FC-48-109-B & FC-48-109-C & FC-48-109-D & FC-48-108-B \\
\hline VDPE, g & 7.00 & 7.00 & 7.00 & 7.00 \\
\hline Acrylic acid, g & 4.25 & 4.25 & 4.25 & 4.25 \\
\hline 1,6-Hexanediol diacrylate, g & 0.00 & 0.25 & 0.50 & 0.75 \\
\hline BPO, g & 0.75 & 0.75 & 0.75 & 0.75 \\
\hline Grafting Yield & $68 \%$ & $65 \%$ & $70 \%$ & $77 \%$ \\
\hline Phosphorus Content, meq/g & 0.62 & 0.65 & 0.68 & 0.66 \\
\hline
\end{tabular}

\begin{tabular}{|l|c|c|c|c|}
\hline Lot \# & FC-48-109-B & FC-48-109-C & FC-48-109-D & FC-48-108-B \\
\hline VDPE, g & 9.00 & 9.00 & 9.00 & 9.00 \\
\hline Acrylic acid, g & 4.25 & 4.25 & 4.25 & 4.25 \\
\hline 1,6-Hexanediol diacrylate, g & 0.00 & 0.25 & 0.50 & 0.75 \\
\hline BPO, g & 0.75 & 0.75 & 0.75 & 0.75 \\
\hline Grafting Yield & $45 \%$ & $58 \%$ & $64 \%$ & $69 \%$ \\
\hline Phosphorus Content, meq/g & 0.62 & 0.67 & 0.78 & 0.73 \\
\hline
\end{tabular}

${ }^{1)}$ For each study, $20.0 \mathrm{~g}$ of vinyl modified silica gel are used.

${ }^{2)}$ Est. error of phosphorus content analyses is less than $5 \%$. 
Table 8: Effect of Acrylic Acid on Grafting Reaction Yield

\begin{tabular}{|l|c|c|c|c|}
\hline Lot \# & FC-48-109-A & FC-48-109-B & FC-48-108-A & FC-48-108-B \\
\hline VDPE, g & 7.00 & 7.00 & 7.00 & 7.00 \\
\hline Acrylic acid, g & 3.25 & 4.25 & 3.25 & 4.25 \\
\hline 1,6-Hexanediol diacrylate, g & 0.00 & 0.00 & 0.75 & 0.75 \\
\hline BPO, g & 0.75 & 0.75 & 0.75 & 0.75 \\
\hline Grafting Yield & $63 \%$ & $68 \%$ & $70 \%$ & $77 \%$ \\
\hline Phosphorus Content, meq/g & 0.63 & 0.62 & 0.66 & 0.66 \\
\hline
\end{tabular}

${ }^{1)}$ For each study, $20.0 \mathrm{~g}$ of vinyl modified silica gel is used.
${ }^{2)}$ Est. error of phosphorus content analyses is less than $5 \%$.

Table 9: Effect of Reaction Temperature and Time in Hydrolysis Reaction

\begin{tabular}{|c|c|c|c|c|}
\hline $\begin{array}{c}\text { Reaction } \\
\text { Temperature }\end{array}$ & $\begin{array}{c}\text { Reaction Time, } \\
\text { Hr. }\end{array}$ & $\%$ Solids & $\begin{array}{c}\text { Acid Content } \\
\text { meq/g }\end{array}$ & $\begin{array}{c}\text { Phosphorus } \\
\text { Content } \\
\text { meq/g }\end{array}$ \\
\hline $85^{\circ} \mathrm{C}$ & 1 & $62.4 \%$ & 2.68 & 0.74 \\
\hline & 3 & $61.9 \%$ & 2.93 & 0.71 \\
\hline & 6 & $59.4 \%$ & 3.02 & 0.72 \\
\hline $90^{\circ} \mathrm{C}$ & 1 & $61.8 \%$ & 2.60 & 0.79 \\
\hline & 3 & $57.1 \%$ & 3.10 & 0.71 \\
\hline & 6 & $55.8 \%$ & 3.16 & 0.59 \\
\hline $95^{\circ} \mathrm{C}$ & 1 & $60.9 \%$ & 2.87 & 0.73 \\
\hline & 3 & $56.8 \%$ & 3.21 & 0.67 \\
\hline & 6 & $54.4 \%$ & 3.15 & 0.55 \\
\hline $100^{\circ} \mathrm{C}$ & 1 & $58.0 \%$ & 3.19 & 0.71 \\
\hline & 3 & $54.8 \%$ & 3.27 & 0.57 \\
\hline & 6 & $53.3 \%$ & 3.09 & 0.55 \\
\hline
\end{tabular}

${ }^{1)}$ Est. error of acid and phosphorus content analyses is less than 5\%. 
the thermal stability tests and the resins show excellent physical stability through these tests.

Percentage Solids: The percentage solid of the representative resin prepared in laboratory scale is $57 \%$. The variance of this value is less than $2 \%$ from batch to batch.

Acid Capacity: The acid content of the representative resin prepared in laboratory scale is $3.3 \mathrm{meq} / \mathrm{g}$. . The variance of this value is less than $0.2 \mathrm{meq} / \mathrm{g}$ from batch to batch. Because the resin contains not only phosphonic acid group but also carboxylic acid groups from the acrylate, the acid capacity is slightly more than double of the phosphorus content of the resin.

Phosphorus Content: The phosphorus content of the representative resin prepared on a laboratory scale is $0.65 \mathrm{meq} / \mathrm{g}$. The variance of this value is less than $0.03 \mathrm{meq} / \mathrm{g}$ from batch to batch. This phosphorus content on this newly developed resin is lower than was proposed in the original test plan. However, during our study, it was realized that the silica-based resin is composed of more than $80 \%$ of silica gel. The grafted polymer which contains all of diphosphonic acid ligands is coated as a thin film on the surface throughout the pores of silica gel. Moreover, the percent solid of silica-based Diphonix is twice that of the polystyrene-based Diphonix resin. Comparing the capacity and quality of these resins on a dry weight basis is not completely appropriate. In practical application, the ion exchange resins are usually measured by volume under wet condition. Under practical conditions, the performance of the two versions of Diphonix resin is similar. The performance, based upon unit volume, of the silica-based Diphonix and polystyrene-based Diphonix in the Fe(III) uptake and column breakthrough is studied and discussed in a later section.

Stability in 3N Nitric Acid: The acid and phosphorus content of the resin were reanalyzed after shaking the resin in $3 \mathrm{~N}$ nitric acid at room temperature for periods of 3 and 7 days. The results shown in Table 10 indicate that the silica supported Diphonix resin is stable in $3 \mathrm{~N}$ nitric acid. The resin also does not show any discoloration after contact with the acid, further indicating the resins acid stability.

Thermal Stability: In the thermal stability test, the results in Table 11 show that both the acid and phosphorus capacities show less than $5 \%$ reduction after one hour of heating at $65^{\circ} \mathrm{C}$.

$\underline{D}_{\underline{w}}$ Measurement of Fe(III) Uptake in Various Concentration of Nitric Acid: The dry weight distribution ratio, $\mathrm{D}_{\mathrm{w}}$, for Fe(III) was measured using tracer level of the radioisotope ${ }^{59} \mathrm{Fe}$ in various concentrations of nitric acid, $1 \mathrm{~N}$ to $5 \mathrm{~N}$. The results plotted in Figure 4 shows that all the measured distribution ratios are in a range slightly above $10^{4}$. This value is an order of magnitude higher than proposed in the test plan.

Kinetic Study of Fe(III) Batch Uptake in 3N Nitric Acid: The uptake kinetics of $\mathrm{Fe}(\mathrm{III})$ in $3 \mathrm{~N}$ nitric acid by silica-based Diphonix and polystyrene-based Diphonix resins 
Table 10: Resin Acid Stability in 3N Nitric Acid

\begin{tabular}{|c|c|c|c|}
\hline \multicolumn{4}{|c|}{ Study of Acid Stability in $3 \underline{N}$ Nitric Acid } \\
\hline \multicolumn{4}{|c|}{ Diphonix } \\
\hline Contact Time, Days & \%Solids & Acid Contents & Phos. Contents \\
\hline 0 & $27.7 \%$ & 6.84 & 1.31 \\
\hline 3 & $27.1 \%$ & 7.20 & 1.31 \\
\hline 7 & $27.1 \%$ & 7.22 & 1.34 \\
\hline \multicolumn{4}{|c|}{ Silica-Based Diphonix, Prepared in 500-mL Reactor } \\
\hline Contact Time, Days & $\%$ Solids & Acid Contents & Phos. Contents \\
\hline 0 & $56.9 \%$ & 3.32 & 0.65 \\
\hline 3 & $56.7 \%$ & 3.23 & 0.62 \\
\hline 7 & $56.1 \%$ & 3.30 & 0.62 \\
\hline \multicolumn{4}{|c|}{ Silica-Based Diphonix, Prepared in 110-liter Reactor } \\
\hline Contact Time, Days & \%Solids & Acid Contents & Phos. Contents \\
\hline 0 & $54.3 \%$ & 3.07 & 0.60 \\
\hline 3 & $55.4 \%$ & 3.08 & 0.58 \\
\hline 7 & $55.3 \%$ & 3.02 & 0.59 \\
\hline
\end{tabular}

Table 11: Resin Thermal Stability Study at $65^{\circ} \mathrm{C}$ for 1 hour

\begin{tabular}{|c|c|c|c|c|}
\hline Size of Reactor & \multicolumn{2}{|c|}{$500-\mathrm{mL}$} & \multicolumn{2}{c|}{110 -liter } \\
\hline Condition & Before & After & Before & After \\
\hline$\%$ Solids & $56.9 \%$ & $55.0 \%$ & $54.2 \%$ & $55.0 \%$ \\
\hline Acid Contents, meq/g & 3.32 & 3.37 & 3.07 & 3.02 \\
\hline Phos. Contents, meq/g & 0.65 & 0.65 & 0.60 & 0.58 \\
\hline
\end{tabular}

${ }^{1)}$ Est. error of acid and phosphorus content analyses is less than $5 \%$. 
Figure 4: The $D_{w}$ of Fe(III) in Various Concentrations of Nitric Acid

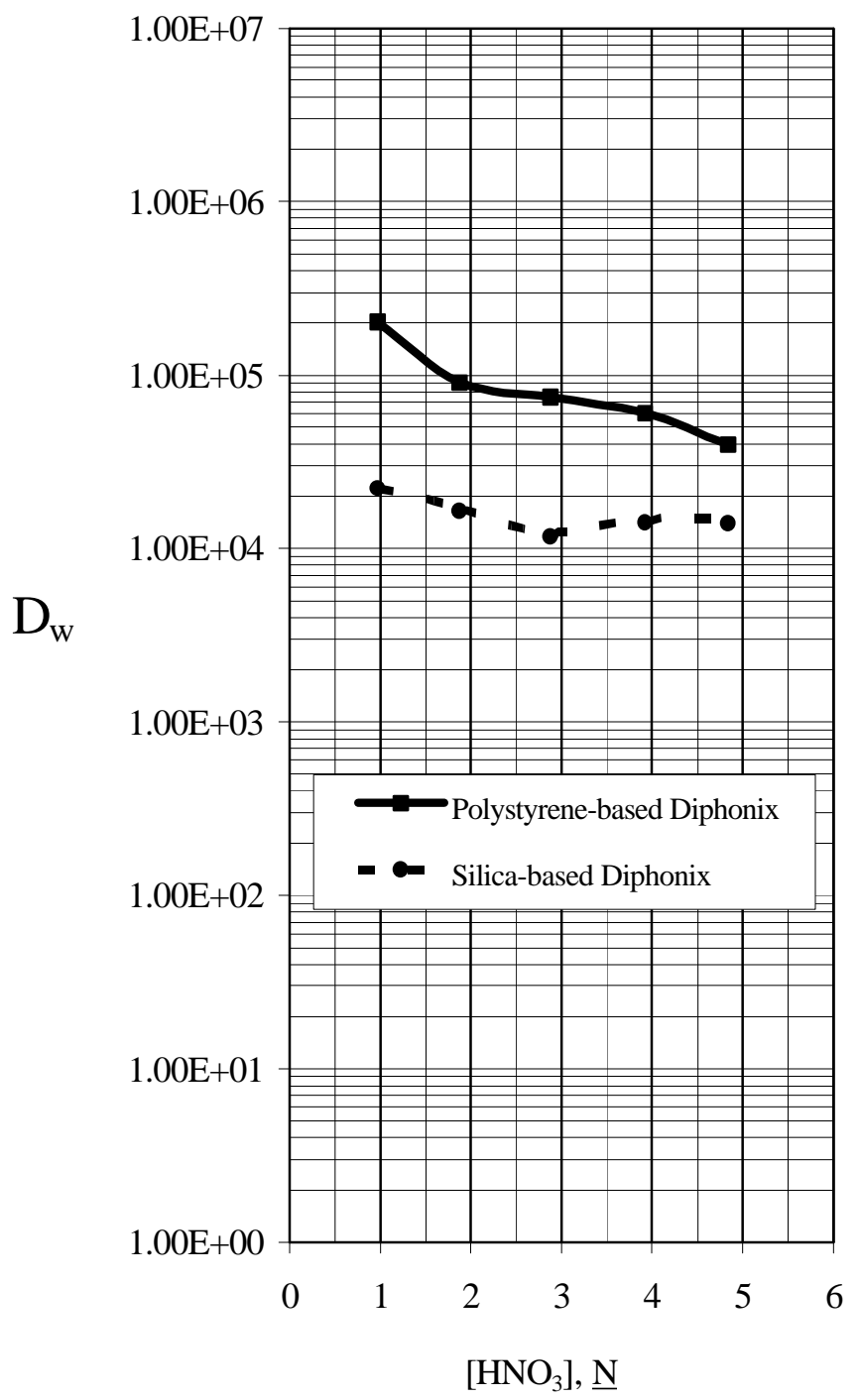


were studied and are compared in Figure 5. The data indicate that silica resin exhibits slightly better kinetics than the polystyrene-based Diphonix resin for Fe(III) uptake.

Fe(III) Breakthrough Curve: Fe(III) breakthrough curves for silica-based Diphonix and polystyrene-based Diphonix were generated using solutions of in $3 \mathrm{~N}$ nitric acid without any salt (i) and in the presence of $4 \mathrm{M}$ sodium nitrate (ii). The results are presented in Figure 6. Observations based on the breakthrough curve data follow:

(i) The Fe(III) loading/breakthrough curve for the silica-based Diphonix resin shows an earlier breakthrough and a capacity for Fe(III) approximately $30 \%$ less than the polystyrene-based Diphonix resin. The difference in capacity between the silica-based and polystyrene based resins is a direct result of the difference in the phosphorus content discussed earlier. The silica-based resin is composed of a core of silica $(\sim 80 \%)$ with only approximately $20 \%$ of the resins total weight consisting of the grafted phosphorus containing polymer.

(ii) The breakthrough curve for the silica-based Diphonix resin remains sharp even in highly salted matrices. The higher water content of the polystyrene-based Diphonix resin results in a higher degree of resin shrinkage in salt solutions with a possible impact on the uptake kinetics. The change in the physical size of the polystyrene-based resin and the resultant hindrance of accessibility of binding sites is the possible cause of the shift in the breakthrough curve for the polystyrenebased resin.

Table 12 summarizes the physical properties that were expected and subsequently obtained for the silica-based Diphonix resin.

\section{Scale-Up Studies}

The formula summarized from the laboratory synthesis has been scaled-up through 2-liter, 22-liter and 110-liter reactors. The complete production flowsheets for the process are presented in Appendix C. The results of each step of the scale-up process are discussed in the following sections:

\section{Synthesis of vinyl modified silica gel}

The quantity of silica gel used for each size of reactor and the vinyl group content of the modified silica gel produced from each size of reactor are summarized in Table 13. The vinyl group content of the resins prepared from each scale-up experiment meet the specification determined from the laboratory study. The resin prepared from the first run in 110-liter reactor shows a slightly higher vinyl group content. This could be due to undersized condensation equipment which did not totally remove the hydrogen bonded water in the azeotrope. The condensation equipment has been redesigned and the 
Figure 5: Kinetics of Fe(III) Uptake in $3 \underline{N}$ Nitric Acid

The Comparison of Silica-Based and Polystyrene-Based Diphonix Resins

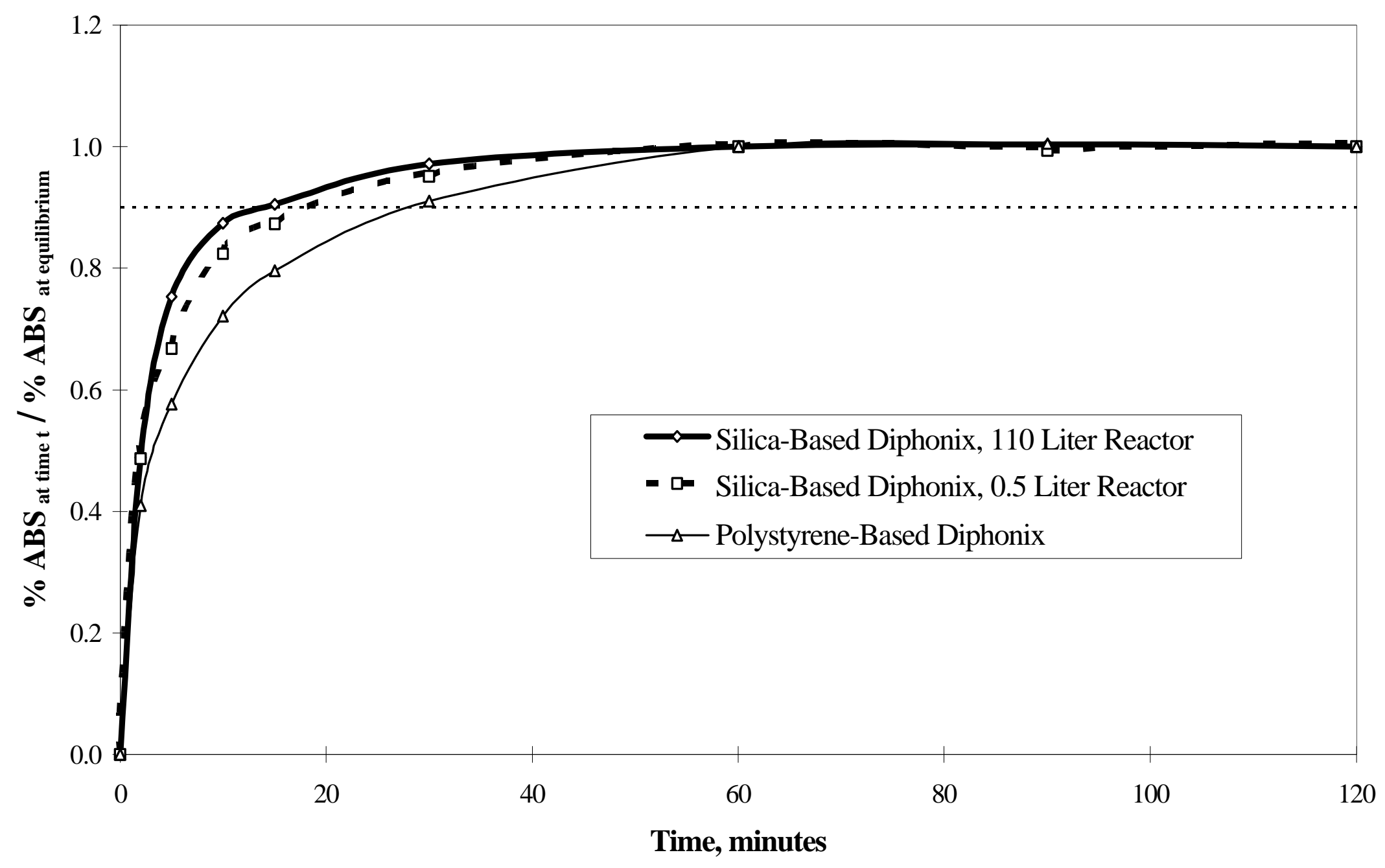


Figure 6: Comparison of Fe(III) Breakthrough Curves and Salt Effect 3N Nitric Acid - 200ppm Fe(III)

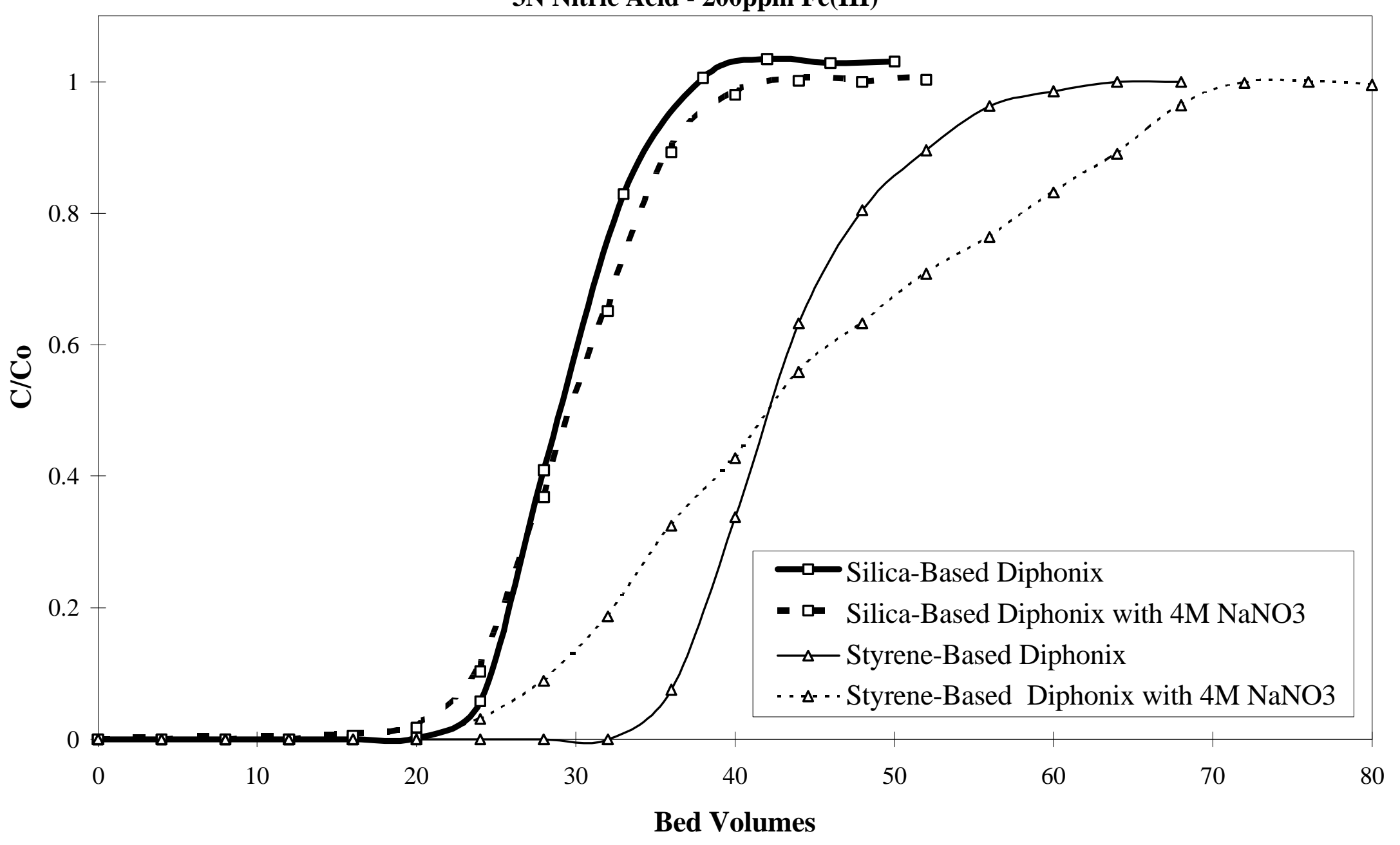




\section{Table 12. Resin Physical Properties Evaluation - Expected vs. Achieved}

\section{$\underline{\text { Test }}$}

Visual Examination

Phosphorus content

Acid capacity

Thermal stability (acid capacity after heating at $65^{\circ} \mathrm{C}$ for one hour)

Fe(III) uptake

Stability in $3 \mathrm{M} \mathrm{HNO}_{3}$

Percent Solids

\section{$\underline{\text { Purpose }}$}

Look for evidence of bead structure problems

Measurement of the ligand sites available for metal ion uptake

Determine the number of cation sites available for exchange

Determine loss of cation sites when resin is heated

Test availability of ligands for metal ion uptake (ferric is a good predictor of performance with actinides)

Test bead stability in strong acid

Determine the dry weight of the resin

\section{Expected Result}

No more than 5 abnormal beads per 100

$1.4 \mathrm{mmol} /$ gram dry resin minimum

2X phosphorus content minimum

Less than 5\% reduction

Distribution coefficient greater than $10^{3}$ at 30 minutes contact time

No bead structure problems; no signs of silica matrix dissolution

Higher solids content compared to polystyrene-based Diphonix ( 30\%)

\section{Achieved}

No evidence of bead structure problems

$0.65 \mathrm{mmol} /$ gram dry resin - see page 21 for explanation

Greater than 2X phosphorus content - see page 21 for explanation

Less than $5 \%$ reduction

Distribution coefficient greater than $10^{4}$ at 30 minutes contact time $1 \mathrm{~N}$ to $5 \mathrm{~N}$ nitric acid

Resin is stable - no sign of structure problems or dissolution

Solids content $=57 \%$ 
performance of azeotrope has become much more efficient in the second large scale reaction.

\section{Synthesis and hydrolysis of VDPE grafted silica gel}

To minimize the manufacturing cost, the grafting and hydrolysis reactions are combined in the scale-up to a single process without dropping the resin from the reaction vessel. In the revised process, the monomer solution is prepared and dissolved in a low boiling point solvent, acetone. The monomer solution is then mixed with vinyl modified silica gel and the $\mathrm{NaCl}$ aqueous solution in the reaction vessel with a mechanical stirrer. The organic solvent, acetone, is slowly removed under the vacuum (25 inches $\mathrm{Hg}$ ) with a slow temperature ramp, $20^{\circ} \mathrm{C}$ to $45^{\circ} \mathrm{C}$, over a period of several hours. After the majority of acetone, $\sim 90 \%$, is removed, the vacuum is released and the grafting reaction started at the desired heating profiles determined from the laboratory study. After the grafting reaction is completed, the resin is washed with water in the reaction vessel and the appropriate amount of $\mathrm{HCl}$ is added to perform the hydrolysis. The combined process was tested in 2-liter and 22-liter reactors. The data in Table 14 indicates that the resins prepared by the combined process described above, in both the 2-L and 22-L reactors, yielded product with capacities comparable to the resin produced in the laboratory study. ${ }^{1}$ After successful completion of the 2-liter and 22-liter reactor runs, the 110-liter runs were performed. Results of the product evaluation at this scale are discussed below. The temperature record of grafting reaction is attached on Appendix B and shown in Figure 7. The grafting reaction does not show any exothermic phenomena in 110-liter size reactor. Hydrolysis reaction in 110-liter reactor produced detectable quantities of volatile side products which were not significant enough to be detected from the 2-liter and 22-liter reactor experiments. The composition of these side products includes methylene chloride, chloroform, 2-chloropropane (the major component), propane, and acetone. The formation of 2-chloropropane is due to the presence of 2-propanol cleaved from the VDPE and the high concentration of hydrochloric acid at elevated temperature. To avoid the formation of chlorinated side-products, the hydrolysis reaction should be further investigated with other acids, e.g. sulfuric acid.

Physical Property Evaluation: The resins prepared in 110-liter reactor show similar physical properties upon visual examination. The analyses of percent solids, acid content, and phosphorus content (Table 14) are comparable to the capacities of the resins prepared in the 2-liter and 22-liter reactors. Thermal stability (Table 11) and acid stability (Table 10) tests indicate that the resin meets the success criteria of less than $5 \%$ reduction in acid content and phosphorus content. The results of kinetic study of Fe(III) batch uptake in 3N nitric acid are presented in Figure 5. The resin prepared from 110-liter

\footnotetext{
${ }^{1}$ During the scale-up to the 110 liter reactor we discovered that Eichrom's reactor could not hold vacuum as low as 25 inches $\mathrm{Hg}$. Consequently, the scale up in 110 liter reactor still adopt the acetone stripping method used in small scale followed by transfer of the monomer impregnated silica gel to the reactor to accomplished the rest of grafting and hydrolysis with the process mentioned above. Toll processors with whom we have discussed the synthesis route have indicated their reactors are capable of holding the required vacuum. Therefore, this limitation pertains only to Eichrom's equipment.
} 
Table 13: Vinyl Group Content of Modified Silica Gel - Scale-up Comparison

\begin{tabular}{|c|c|c|c|}
\hline Size of Reactor & 2-liter & 22-liter & 110-liter \\
\hline $\begin{array}{c}\text { Quantity of Silica Gel Used for } \\
\text { Modification Reaction }\end{array}$ & $400 \mathrm{~g}$ & $2240 \mathrm{~g}$ & $20 \mathrm{Kg}$ \\
\hline $\begin{array}{c}\text { Vinyl Group Content of Product } \\
\text { meq/g }\end{array}$ & 0.90 & 0.92 & $\begin{array}{c}\text { Run 1: } 0.98 \\
\text { Run 2: } 0.90\end{array}$ \\
\hline
\end{tabular}

${ }^{1)}$ Est. error of vinyl group content analyses is less than $5 \%$.

Table 14: Physical Property Comparison of Silica-based Diphonix Prepared at Different Scales

\begin{tabular}{|c|c|c|c|}
\hline Size of Reactor & 2-liter & 22-liter & 110-liter \\
\hline Batch \# & JW-49-183 & FC-60-014 & JW-65-040-B \\
\hline$\%$ Solid & $55.7 \%$ & $56.0 \%$ & $54.3 \%$ \\
\hline Acid Content, meq/g & 3.22 & 3.14 & 3.07 \\
\hline Phos. Content, meq/g & 0.62 & 0.60 & 0.60 \\
\hline
\end{tabular}

${ }^{1)}$ Est. error of acid and phosphorus content analyses is less than $5 \%$. 
Figure 7: Temperature Record of Grafting Reaction in 110-liter Reactor

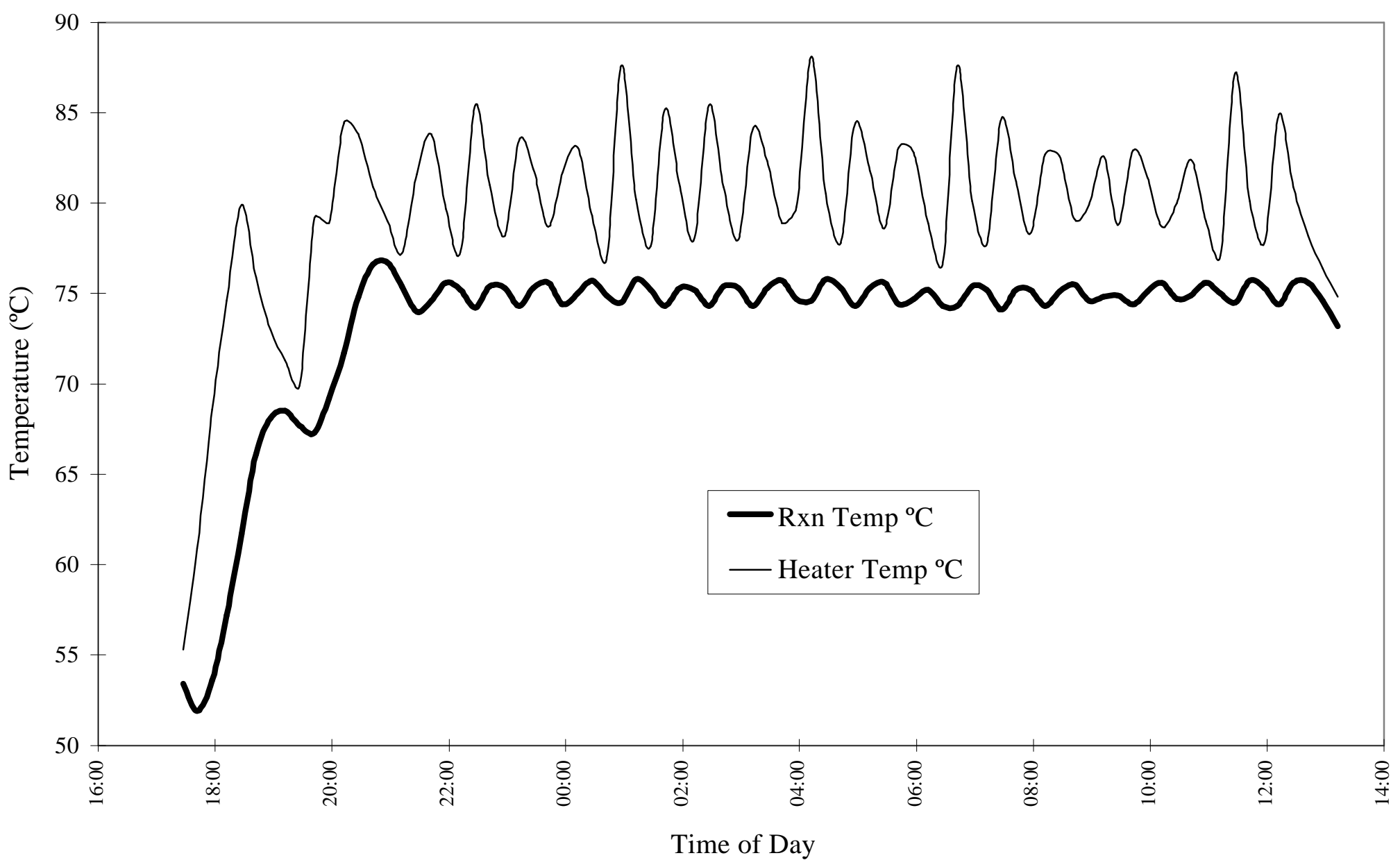


Figure 8: Comparison of Fe(III) Breakthrough Curves

3N Nitric Acid - 200ppm Fe(III)

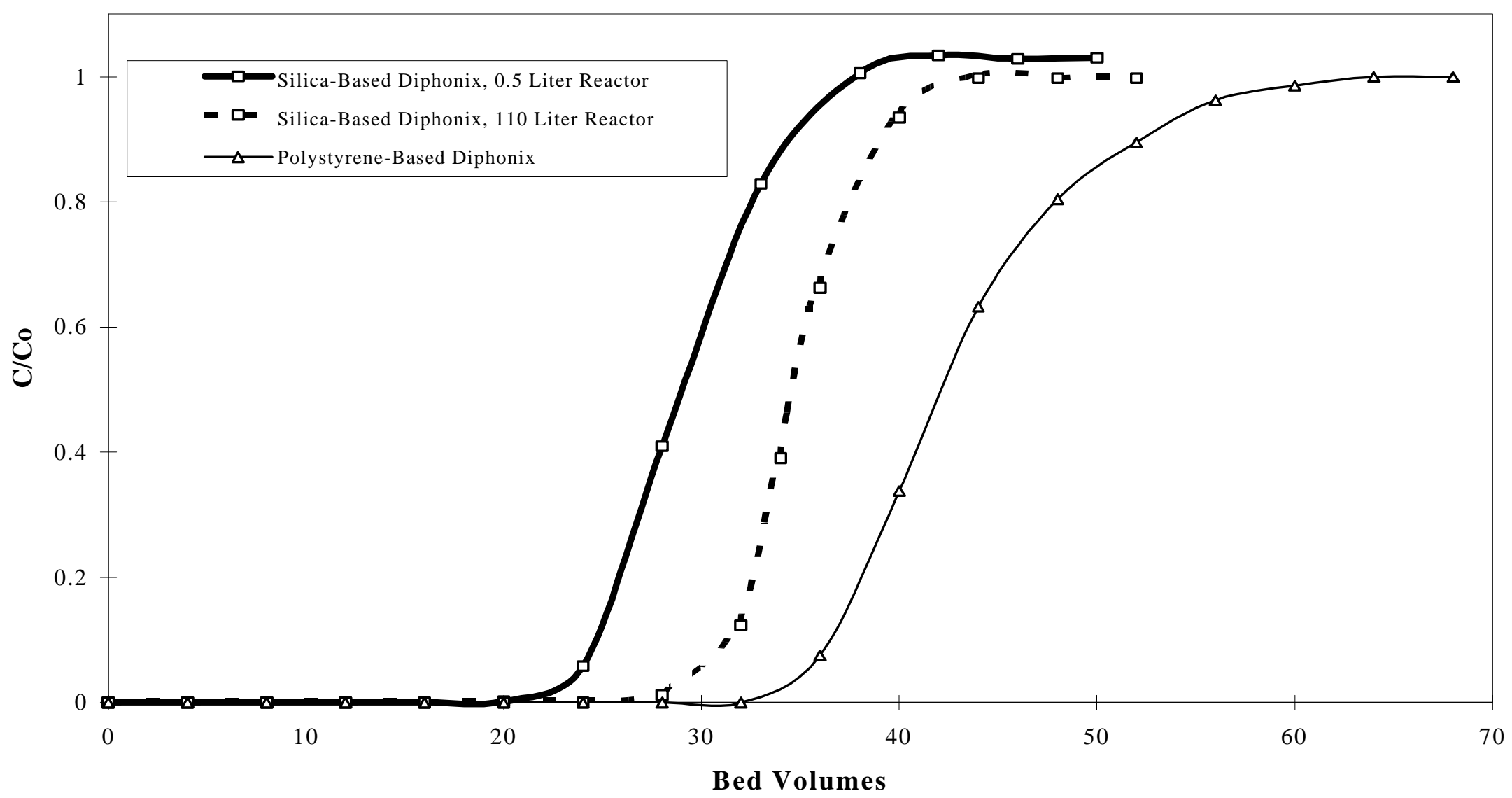


reactor has same kinetic performance as the resin obtained from laboratory synthesis. The $\mathrm{Fe}(\mathrm{III})$ breakthrough curves of both resins prepared in laboratory scale and pilot scale are compared in Figure 8. The resin prepared from 110-liter reactor demonstrates the expected sharp breakthrough. The Fe(III) loading capacities for polystyrene-based Diphonix and silica-based Diphonix (both 50-100 mesh size) are compared in Table 15. These results show the polystyrene-based resin to have approximately $15 \%$ more capacity. We have previously demonstrated uptake and kinetics to be nearly the same for the two resins. The more porous silica-based Diphonix may exhibit higher capacities and faster kinetics when compared to the polystyrene based resin for typical high salt wastes.

\section{Table 15: Comparison of Fe(III) Loading Capacities in 3 N Nitric Acid,} on Volume Bases

\begin{tabular}{|c|c|c|}
\hline Resins & $\begin{array}{c}\text { Polystyrene-based } \\
\text { Diphonix }\end{array}$ & $\begin{array}{c}\text { Silica-based } \\
\text { Diphonix }\end{array}$ \\
\hline Size of Reactor & 1000 -gallon & $\begin{array}{c}110 \text {-liter } \\
(30 \text {-gallon })\end{array}$ \\
\hline $\begin{array}{c}\text { Total uptake of Fe(III), mg, } \\
\text { per mL of Resin }\end{array}$ & 8.4 & 7.1 \\
\hline
\end{tabular}

\section{Economic Evaluation}

The economic evaluation of silica-based Diphonix is based upon the data collected from running the synthesis route in Eichrom's 110-liter reactor. The detailed cost calculations presented in Table 16 provide an approximate breakdown of costs between labor and materials. The chemicals, other than VDPE, are purchased in liter bottle to 5 gallon drum sizes. Further scale-up will allow for dramatic cost reductions when it is possible to obtain some chemicals in the 55-gal drum or larger quantities. Based on our experience with polystyrene-based Diphonix resin scale-up, the cost of these chemicals drops to a fraction of their current pilot-scale cost. The silica gel (Davisil 645) is currently purchased in $50 \mathrm{~kg}$ units. Purchasing in units as large as a metric ton will also significantly lower the cost of silica gel.

The labor costs are high even at the 110-liter scale. This is due primarily to equipment size limitations at our facility. For example, the size of our current rotary evaporator limits the quantity of silica that can be handled while removing the acetone in the grafting reaction, and consequently acetone evaporation becomes a major cost at this scale. However, based on discussions with our toll processor, this limitation will not exist when using larger industrial scale equipment. Consequently, when the synthesis is moved 
Table 16: Cost Calculation for Silica-Based Diphonix Resin in 110-L Reactor

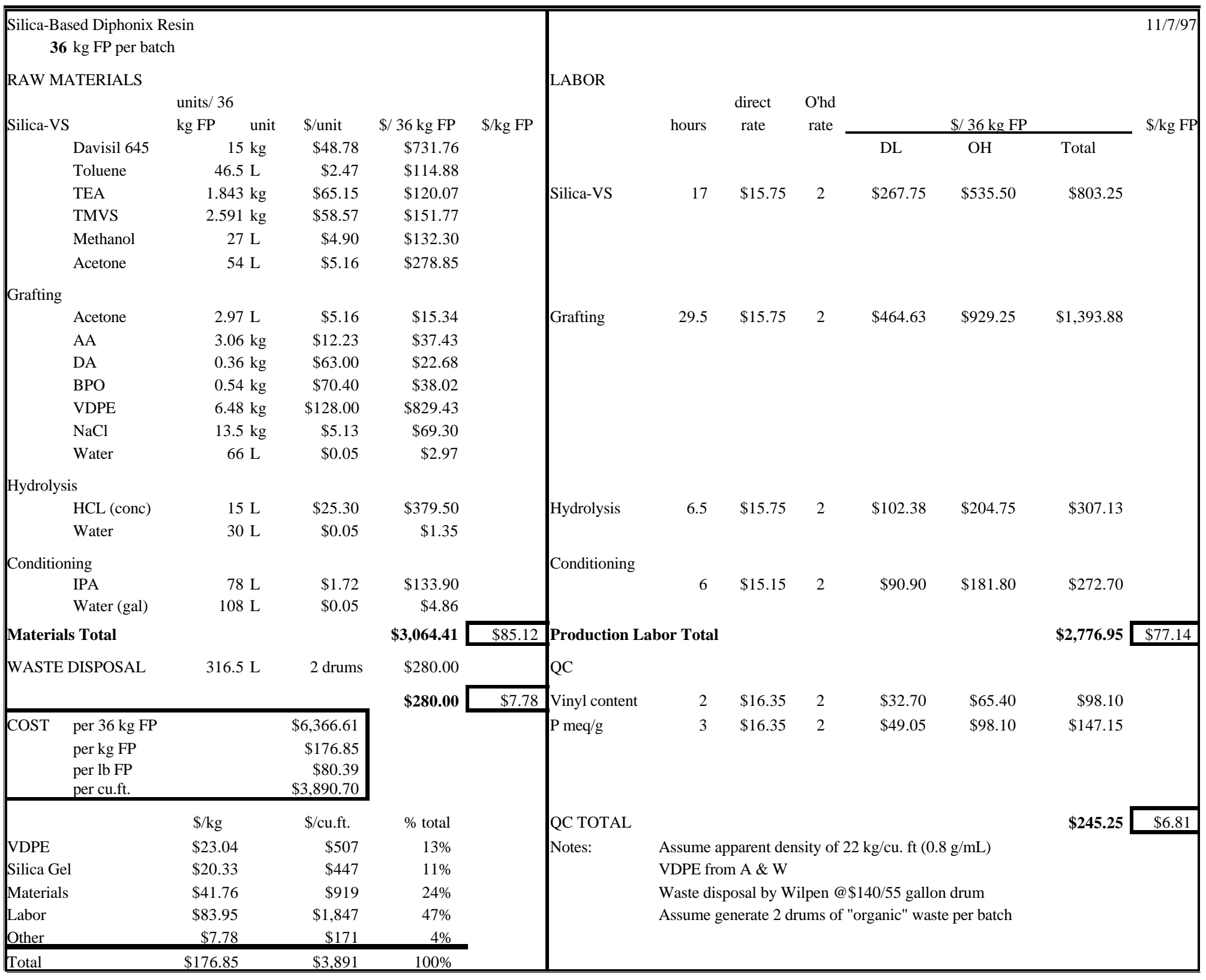


Table 17: Cost Calculation for Polystyrene-Based Diphonix Resin in 110-L Reactor

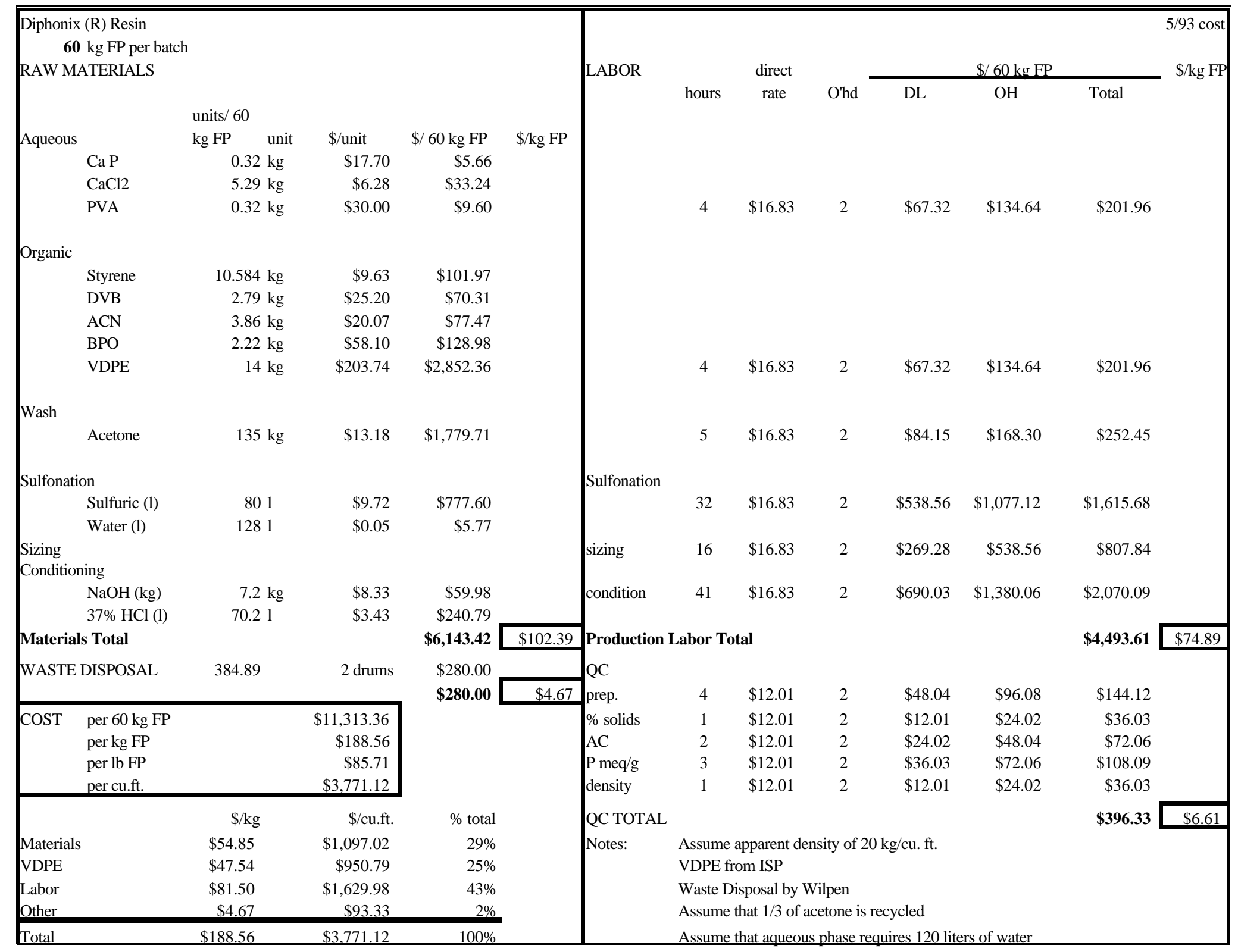


to a full scale industrial plant for manufacturing, labor cost per kilogram of finished product could drop more than an order of magnitude.

Historical cost evaluation for polystyrene-based Diphonix resin in the same 110liter reactor is presented in Table 17. This data indicates that the cost for making silicabased and polystyrene-based Diphonix resins are comparable at the 110-liter scale.

\section{Conclusion}

A new version of silica based Diphonix resin has been successfully developed. An economical three-step synthetic route, instead of the originally proposed four-step reaction route, has been demonstrated. The new product has very strong physical properties and lost less than $5 \%$ of capacities in both acid and thermal stability tests. The affinity test to $\mathrm{Fe}(\mathrm{III})$ measured in various concentrations of nitric acid indicates that all $\mathrm{D}_{\mathrm{w}}$ 's are one magnitude higher than the target value. In the kinetic and breakthrough curve studies of $\mathrm{Fe}(\mathrm{III})$ in $3 \mathrm{~N}$ nitric acid, the new resin exhibits better performance than the polystyrenebased Diphonix resin while the loading capacity is slightly lower. The process has been successfully demonstrated twice in a 110-liter pilot reactor. Both reactions produced product of same quality as the resin prepared in laboratory scale. The economic evaluation indicates that the cost for making silica-based and polystyrene-based Diphonix resin at the 110-liter reactor scale is comparable.

Table 18 provides a concise summary of the current effort against the success criteria originally required.

\section{Table 18. Comparison of Required Success Criteria vs Success Achieved}

\begin{tabular}{|c|c|c|c|}
\hline Task & Task Description & $\begin{array}{c}\text { Required Success } \\
\text { Criteria }\end{array}$ & Criteria Achieved \\
\hline 1 & Design and Develop & & \\
\hline $\mathbf{1 A}$ & Functionalize Silica Gel & $>90 \%$ coverage & Yes \\
\hline 1B & Graft Ligands & $>80 \%$ grafting & $\mathrm{N} / \mathrm{A}^{\mathrm{a}}$ \\
\hline $1 \mathrm{C}$ & Functionalize Ligands & $1.4 \mathrm{meq} \mathrm{P} / \mathrm{g}$ resin & No - see text page 21 \\
\hline 1D & Hydrolysis of Ligands & $>95 \%$ ligand hydrolysis & Yes \\
\hline 2 & $\begin{array}{l}\text { Physical Properties } \\
\text { Evaluation }\end{array}$ & See Table 12 & Yes \\
\hline 3 & 2-liter Scale-Up & $\begin{array}{l}\text { Meet Task } 2 \text { Properties } \\
\text { Evaluation }\end{array}$ & Yes \\
\hline 4 & 110-liter Scale-up & $\begin{array}{l}\text { Meet Task } 2 \text { Properties } \\
\text { Evaluation and Pass } \\
\text { Economic valuation }\end{array}$ & Yes \\
\hline
\end{tabular}




\section{Recommendations for Future Work}

The synthesis and scale up of silica-based Diphonix have been accomplished as proposed. Several recommendations for further work are given below. These recommendations are in addition to the effort currently outlined in the Optional Phase of this program. Accomplishing these recommended studies will make the process easier to scale-up to the large industrial scale (1000 gallon reactors) and provide additional information about the character and performance of this product. Production safety will be enhanced along with further cost reductions. The recommendations are as follows:

(1) Further Study of Hydrolysis of VDPE Grafted Silica Gel: Due to the formation of 2-chloropropane as a side product in the current hydrolysis reaction, the hydrolysis reaction should be further investigated using sulfuric or other acids. The study can be focused on the reaction time and temperature and the concentration of sulfuric acid. By removing chlorine from the reactants, the production of 2-chloropropane will be eliminated.

(2) Substitution of Other Silica Gel Materials: Based upon the preliminary information available, Davisil-645 was chosen as the silica gel for the Phase 1 effort. However, testing alternate silica gels made by other manufacturers could provide information for improving the performance and cost of the silicabased Diphonix resin.

(3) Examine Possible use of Larger Particle Size Silica Material: The synthesis work in this effort was performed using 50-100 mesh silica gel. Since pressure drop across a resin column is always a concern from an engineering point of view, synthesis of silica-based Diphonix using other particle sizes, such as 2050 mesh, should also be studied. Improved performance may be obtained due to the more porous structure of the silica-based resin when compared to the polystyrene based material.

(4) Examine Alternative Solvents for the Grafting Reaction: Acetone, used in grafting reaction, is a flammable solvent. Due to safety consideration during full scale production, the grafting reaction should be studied further with alternative solvents. Our toll processor has indicated that they can handle acetone safely, but we believe it would be prudent to perform this study.

The above four recommendations can be accomplished as part of the Optional Program at no additional cost. The overall resin quality will be improved. Further, improvements in safety and additional cost reductions may result. 
Appendix A 


\section{Ion Exchange Resin Percent Solids}

\section{Introduction}

\subsection{Description}

This procedure describes how to determine the percent solids of ion exchange resins. This method is based on ASTM Designation D2187-93, test method B. Perform this test whenever specified in document \# PRD-3030 -- Diphonix ${ }^{\circledR}$ Resin Final Product Inspection Requirements.

This test is dependent on both the $\mathrm{pH}$ and resin particle size. The resin's state of hydration varies with $\mathrm{pH}$ and particle size. As a result, fully hydrated beads (pH 7) have a lower \% solids than less hydrated ones (e.g., pH 1). Similarly, smaller beads hold less water per gram than their larger counter parts. Thus, small mesh beads (e.g., $<100$ mesh) have a higher \% solids than larger ones (e.g., 18-40 mesh). For this reason, the $\mathrm{pH}$ and mesh size of the resin particles must be determined prior to testing.

\subsection{Definitions}

1.2.1. Ion exchange resin: a solid matrix bead incorporating pores. The bead exchanges one ion for another. The pores fill with water when the resin is wet.

1.2.2. Percent Solids: the weight percentage of solid material in the ion exchange resin. More highly cross linked beads have higher \% solids because they have fewer spaces for water.

\subsection{Reference Documents}

1.3.1. Document \# PRD-3030 -- Diphonix Resin Quality Assurance

1.3.2. ASTM Designation: D2187-93. American Society for Testing and Materials, Test Method B.

\section{Preparation}

2.1. Receive the Resin Quality Control Form from the Quality Manager.

2.2. Get resin to be tested from the file sample.

2.3. Dry the resin samples using a vacuum and a fritted glass Buchner funnel.

2.4. Record the date, the resin lot, and the mesh size of the resin to be tested (determined by production manager) in a laboratory notebook.

2.5. Get 3 scintillation vials for each resin sample. If these are not clean, wash them with soap and water, rinse them with de ionized water, and allow them to dry.

2.6. An analytical balance (Readability $0.1 \mathrm{mg}$, e.g. Mettler, Model AE200, accurate to $0.3 \mathrm{mg}$ )

Note: Calibration procedures are specified in Inspection and Test Equipment Control, document \# QA-0004. 


\section{3. $\quad$ Procedure}

3.1. Dry three scintillation vials in an approximately $110^{\circ}$ oven for at least 15 minutes.

3.2. Cool scintillation vials at least $1 / 2$ hour in desiccator.

3.3. Weigh each vial. Record weight to the nearest $0.1 \mathrm{mg}(\mathrm{A})$.

3.4. Place $2.0 \pm 0.2$ grams of resin into each vial. Record the weight to the nearest $0.1 \mathrm{mg}$ as the "wet" weight (B).

3.5. Dry vials for approximately 16 hours in an approximately $110^{\circ}$ oven.

3.6. Cool vials for at least 30 minutes in desiccator.

3.7. Weigh each vial. Record the weight of each vial to the nearest $0.1 \mathrm{mg}(\mathrm{C})$.

\section{Calculations:}

4.1. Calculate the dry weight $=\mathrm{C}-\mathrm{A}$. Record to the nearest $0.1 \mathrm{mg}$.

4.2. Calculate $\%$ Solids $=((\mathrm{C}-\mathrm{A}) / \mathrm{B}) \times 100$. Record to the nearest $0.05 \%$.

4.3. Calculate the average \% Solids. Record to the nearest $0.1 \%$.

4.4. Calculate the standard deviation \% Solids. Record to 3 significant digits.

\section{Records}

5.1. Sign and date the notebook page(s). Photocopy the page(s). Using $95 \%$ reduction works well. 


\section{Acid Capacity Test for Ion Exchange Resin}

\section{Introduction}

\subsection{Description}

This procedure describes how to determine the acid capacity of cation exchange resins. This method is based on ASTM Designation D2187-93, test method F. Perform this test for each lot of Diphonix ${ }^{\circledR}$ resin as part of the Diphonix resin quality testing.

The acid capacity is calculated using the percent solids. Therefore, it is dependent on both the $\mathrm{pH}$ and resin particle size since percent solids is dependent on the resin's state of hydration that varies with $\mathrm{pH}$ and particle size. As a result, fully hydrated beads ( $\mathrm{pH} 7$ ) have a lower $\%$ solids and a higher acid capacity than less hydrated ones (e.g., pH 1). Similarly, smaller beads hold less water per gram than their larger counter parts. Thus small mesh beads (e.g., $<100$ mesh) have a higher \% solids and lower acid capacity than larger ones (e.g., 18-40 mesh). For this reason, the $\mathrm{pH}$, mesh size of the resin particles, and percent solids must be determined prior to testing.

\subsection{Definitions}

1.2.1. Acid Capacity: The amount of acidic sites contained in a given weight of dry resin. [meq/gram]

\subsection{Reference Documents}

1.3.1. Document \# QA-3030 -- Diphonix Resin Quality Assurance

1.3.2. ASTM Designation: D2187-93. American Society for Testing and Materials, Test Method F.

1.3.3. Document \# QA-3101 -- Preparation of Solutions for Acid Capacity Testing

\section{Preparation}

2.1. Get a laboratory notebook to record all work.

2.2. Get the resin to be tested.

2.3. Dry 10 - 20 grams of resin using a vacuum and a fritted glass Buchner funnel.

2.4. Record the date, the resin lot, the resin mesh size, and the percent solids . 
2.5. Get equipment. If glassware is not clean, wash it with soap and water, rinse it with de-ionized water, and allow it to dry.

2.5.1. One $250 \mathrm{~mL}$ Erlenmeyer flask

2.5.2. Two $125 \mathrm{~mL}$ Erlenmeyer flasks

2.5.3. One $50 \mathrm{~mL}$ buret (Class A)

2.5.4. A buret stand

2.5.5. One $25 \mathrm{~mL}$ pipet (Class A)

2.5.6. One $100 \mathrm{~mL}$ pipet (Class A)

2.5.7. An analytical balance (Calibrated, accurate to $0.1 \mathrm{mg}$, e.g. Mettler, Model AE200)

Note: Calibration procedures are specified in Inspection and Test Equipment Control, document \# QA-0004.

\section{Reagents}

3.1. $0.1 \mathrm{~N}$ sodium hydroxide/5\% sodium chloride solution, standardized. (See Preparation of Solutions for Acid Capacity Testing, document \# QA3101.) Record the normality of the base solution.

3.2. $0.1 \mathrm{~N}$ sulfuric acid solution, standardized. (See Preparation of Solutions for Acid Capacity Testing, document \# QA-3101.) Record the normality of the acid solution.

3.3. Phenolphthalein indicator. (See Preparation of Solutions for Acid Capacity Testing, document \# QA-3101.)

\section{4. $\quad$ Procedure}

4.1. Weigh 1.5 - 2 gram samples of resin dried by Buchner funnel into the 250 $\mathrm{mL}$ Erlenmeyer flask. Record the actual weight (A) to 0.0001 grams.

4.2. Using a class A pipet, measure $200.0 \mathrm{~mL}$ of standardized $0.1 \mathrm{~N}$ sodium hydroxide/ $5 \%$ sodium chloride solution into the flask. Add a stir bar to the flask and cover the flask with parafilm. Record the volume (B).

4.3. Stir slowly on a magnetic stir plate for approximately 16 hours to allow resin to equilibrate in the sodium hydroxide solution.

4.4. Remove the flask from the stir plate and allow the resin to settle.

4.5. Using a class A pipet, transfer $25.0 \mathrm{~mL}$ of solution into a clean $125 \mathrm{~mL}$ Erlenmeyer flask. (Be careful not to transfer any resin.) Record the volume transferred $(\mathrm{C})$. Add 2 drops of phenolphthalein indicator and the solution will turn pink-red.

4.6. Using standardized $0.1 \mathrm{~N}$ sulfuric acid solution, titrate to the endpoint (solution goes from pink to clear). Record the initial (D) and the final volumes $(\mathrm{E})$ of acid .

4.7. Repeat steps $4.6 \& 4.7$ at least one additional time. 


\section{Calculations}

5.1. Calculate the acid volume used, $\mathrm{V}_{\text {acid }}=\mathrm{E}-\mathrm{D}$. Record to the nearest 0.05 $\mathrm{mL}$.

5.2. Calculate the acid capacity

$$
\text { acid capacity }=8 *\left[\left(\mathrm{C} * \mathrm{~N}_{\mathrm{NaOH}}\right)-\left(\mathrm{V}_{\text {acid }} * \mathrm{~N}_{\mathrm{H}_{2} \mathrm{SO}_{4}}\right)\right] /(\mathrm{A} * \% \text { solids })
$$

where, $\mathrm{A}$ is the weight dry resin,

$\mathrm{C}$ is the volume of solution (approximately $25 \mathrm{~mL}$ ), $\mathrm{N}_{\mathrm{NaOH}}$ is the normality of the sodium hydroxide, $\mathrm{V}_{\text {acid }}$ is the volume of acid used,

$\%$ solids is the measured percent solids of the resin, and $\mathrm{N}_{\mathrm{H}_{2} \mathrm{SO}_{4}}$ is the normality of the sulfuric acid.

5.3. Calculate the average acid capacity. Record to the nearest $0.01 \mathrm{meq} / \mathrm{g}$.

5.4. Calculate the standard deviation of the acid capacity. Record to 3 decimal places.

\section{6. $\quad$ Records}

6.1. Sign and date the notebook pages. 


\section{Phosphorus Content by Spec-20}

\section{Introduction}

\subsection{Description}

This procedure describes how to determine the phosphorus content of Eichrom's Diphonix ${ }^{\circledR}$ resin using a Spec-20.

\subsection{Reference Documents}

1.2.1. Document \# QA-0004 -- Inspection and Test Equipment Control

1.2.2. Document \# QA-3030 -- Diphonix Resin Finished Product Inspection Requirements

1.2.3. Gordon, Arnold J. and Richard A. Ford. The Chemist's Companion: A handbook of Practical Data, Techniques, and References. Wiley Interscience, New York. 1972.

\section{Preparation}

Note: Persons performing this procedure are responsible for observing proper safety precautions. Safety precaution information is given in the MSDS for each chemical.

2.1. Get equipment. If glassware is not clean, wash it with $\mathrm{NaOH} / 2$-Propanol solution. DO NOT CLEAN THE GLASSWARE WITH SOAP OR DETERGENT. Glassware must be phosphate free!

Note: $\mathrm{NaOH} / 2$-Propanol solution is the same as the base bath. Directions for preparation are in "The Chemist's Companion", p. 429.

2.1.1. $100 \mathrm{~mL}$ beaker

2.1.2. Watch glass

2.1.3. Hot plate(Corning Model PC-320)

2.1.4. $50 \mathrm{~mL}$ volumetric flask (class A)

2.1.5. $100 \mathrm{~mL}$ volumetric flask (class A)

2.1.6. $200 \mu \mathrm{L}$ autopipettor (calibrated)

2.1.7. $25 \mathrm{~mL}$ volumetric pipet (class A)

2.1.8. $5 \mathrm{~mL}$ measuring device $(5 \mathrm{~mL}$ autopipettor or $10 \mathrm{~mL}$ graduated cylinder, approximate measurement acceptable)

2.1.9. Spec-20 (Must be warmed at $470 \mathrm{~nm}$ for 30 minutes before use to stabilize readings)

2.1.10. Analytical Balance (0.0001 g readability, calibrated)

Note: The Spec-20 calibration procedure is described in Appendix A. All other calibration procedures are listed in document \# QA-0004. 
2.2. Get sample and reagents:

2.2.1. Resin (Dry about $2 \mathrm{~g}$ sample in a $110^{\circ} \mathrm{C}$ oven for about 16 hours. Cool the sample to room temperature in a desiccator before starting analysis.)

2.2.2. Copper sulfate solution, $1 \underline{\mathrm{M}}\left(\approx 16 \mathrm{~g}\right.$ of $\mathrm{CuSO}_{4}$ in $100 \mathrm{~mL}$ of DI water)

2.2.3. Concentrated sulfuric acid, reagent grade

2.2.4. DI water (ASTM Type I)

2.2.5. Potassium persulfate (or sodium persulfate), reagent grade $(98+\%)$

2.2.6. Approximately $6 \underline{\mathrm{N}} \mathrm{NaOH}_{(\mathrm{aq})}$

2.2.7. Vanadate-Molybdate reagent (Preparation procedure is in Appendix B)

\section{Procedures}

For each sample, perform the following procedure in duplicate.

3.1. Weigh $20-25 \mathrm{mg}$ of dry resin into a clean, dry $100 \mathrm{~mL}$ beaker. Record actual weight (A) to $0.1 \mathrm{mg}$ in notebook.

CAUTION: Steps 3.2 - 3.8 must be done in a chemical fume hood.

3.2. Add $100 \pm 10 \mu \mathrm{L}$ of copper sulfate solution and approximately $5 \mathrm{~mL}$ of concentrated sulfuric acid to the beaker.

(The beaker is transferred onto a hot plate before adding sulfuric acid. DO NOT put more than four beakers on each hot plate. Add sulfuric acid gently to the beaker in order to avoid splashing any resin beads up onto the beaker wall. All beads must be in the liquid, either floating or sunken.)

3.3. Heat the beaker on hot plate with a watch glass on top for 2 hours to digest the beads (The temperature adjustment knob is set at "5").

Note: The beads slowly dissolve during the heating.

IF the solution does not turn clear by the end of digestion, heat the sample for an additional 30 minutes until the solution turns clear. IF the solution turns to clear before the end of 2 hours of heating, remove the sample from the hotplate when the volume is $50 \%$ (or less) of the original volume.

3.4. Cool the solution to room temperature and dilute the residue with approximately $75 \mathrm{~mL}$ of DI water. Add $2.0 \mathrm{~g}( \pm 0.1)$ potassium persulfate.

3.5. Boil gently on hotplate for about 2 hours. (The temperature adjustment knob is set at " 3 ". The final volume is about $25-35 \mathrm{~mL}$. DO NOT let the solution get dry.)

3.6. Cool the solution to room temperature.

3.7. Adjust the $\mathrm{pH}$ of the solution with $6 \underline{\mathrm{N}} \mathrm{NaOH}_{\text {(aq) }}$ until the solution turns cloudy; return the solution to neutral by adding dilute sulfuric acid(2\%) until the solution turns clear. 
3.8. Transfer the solution to a $100 \mathrm{~mL}$ volumetric flask. Dilute to the mark with DI water. This is the sample solution.

Note: If the Spec-20 is not warming up now, wait about 15 minutes before continuing.

3.9. Pipette $25 \mathrm{~mL}$ of above sample solution to a $50 \mathrm{~mL}$ volumetric flask.

3.10. Add $10 \mathrm{~mL}$ of Vanadate-Molybdate reagent, using a pipet, to the sample solution. Dilute to the mark with DI water. The Vanadate-Molybdate solution reacts with phosphorus to turn the solution yellow.

Note: Vanadate-Molybdate reagent is $\mathrm{pH}$ sensitive. It is important that the $\mathrm{pH}$ of the sample solution be neutral, as described in step 3.8.

3.11. After approximately 15 minutes, read the absorbance (B) of the sample(s) at $470 \mathrm{~nm}$. Record the absorbance to 0.001 .

\section{Calculations}

4.1. Calculate the total phosphorus content (mg) [C] in the sample based upon the intercept and slope of the calibration curve.

$$
\mathrm{C}=\frac{\text { B-Intercept }}{\text { Slope }}
$$

4.2. Calculate the phosphorus content (meq/g) of each gram of dry Diphonix resin [D].

$$
\mathrm{D}=\frac{\mathrm{C} \times 4}{30.974 \times \mathrm{A}}
$$

4.3. Calculate the relative standard deviation (RSD) of the duplicate samples. IF $\mathrm{RSD}>3 \%$, repeat the phosphorus for the sample.

$$
\mathrm{RSD}=\frac{\mathrm{D}(\text { sample } 1)-\mathrm{D}(\text { average })}{\mathrm{D}(\text { average })} \times 100 \%
$$

\section{Records}

5.1. Record all data in a research notebook. Sign all pages. 


\section{Appendix A. Calibration Curve Preparation}

\section{Introduction}

\subsection{Description}

This appendix describes how to prepare calibration standards for the phosphorus analysis procedure.

\subsection{Reference Documents}

1.2.1. Document \# QA-0004 -- Inspection and Test Equipment Control

\section{Preparation}

Note: Persons performing this procedure are responsible for observing proper safety precautions. Safety precaution information is given in the MSDS for each chemical.

2.1. Get equipment. If glassware is not clean, wash it with NOCHROMIX solution. DO NOT CLEAN THE GLASSWARE WITH SOAP OR DETERGENT.

Glassware must be phosphate free!

2.1.1. One $100 \mathrm{~mL}$ volumetric flask (class A )

2.1.2. Four $50 \mathrm{~mL}$ volumetric flasks (class A)

2.1.3. One $5 \mathrm{~mL}$ autopipettor (Calibration is not required)

2.1.4. One $200 \mu \mathrm{L}$ autopipettor (calibrated, record ID \# to notebook)

2.1.5. An analytical balance (Accurate to $0.1 \mathrm{mg}$, e.g. Mettler, Model AE200)

2.1.6. Spec-20

Note: Calibration procedures are specified in Inspection and Test Equipment Control, document \# QA-0004.

\subsection{Get chemicals}

2.2.1. Potassium phosphate, monobasic crystal (99\%, reagent grade)

2.2.2. DI water (ASTM Type I)

2.2.3. Vanadate-Molybdate reagent, See Appendix B of this procedure.

\section{Preparation of calibration stock solution}

This section describes how to prepare the calibration stock solution. The calibration solution lasts three months when properly stored (i.e. tightly capped and stored at room temperature). Compare the $300 \mu \mathrm{L}$ solution absorbance with the labelled absorbance to verify the stock solution integrity. If the deviation $>5 \%$, discard the solution and prepare a new calibration stock solution.

3.1. Weigh $460 \pm 10 \mathrm{mg}$ of potassium phosphate into a clean, dry $100 \mathrm{~mL}$ volumetric flask.

3.2. Dilute to mark with DI water. Shake gently until the solids are completely dissolved.

3.3. Label the flask with the actual potassium phosphate weight and the preparation date. Record the actual weight (F) in a notebook. After the absorbances have been read, label the solution with the absorbance of the $300 \mu \mathrm{L}$ calibration point. 


\section{Preparation of calibration solutions}

The calibration solutions are used to generate the phosphorus calibration curve. Prepare the solutions with the samples to be analyzed. The calibration solutions cannot be reused. The calibration solutions and sample solution(s) must be read during the same session. All readings must be done between 15-30 minutes after the solution preparation.

4.1. Pipet 0 (blank), 100 (point 1), 300(point 2), and 500(point 3) $\mu \mathrm{L}$ of calibration stock solution into four $50 \mathrm{~mL}$ volumetric flasks.

4.2. Add about $10 \mathrm{~mL}$ DI water to each flask. Swirl for about 5 seconds.

4.3. Add $10 \mathrm{~mL}$ Vanadate-Molybdate reagent to each flask. Dilute to mark with DI water.

4.4. After 15 minutes, zero the absorbance of the instrument (Spec-20) with the blank. Then read the absorbance of the calibration solutions at $470 \mathrm{~nm}$.

Note:Prepare the sample solution(s) and the calibration solutions at the same time. Read the sample solution(s) immediately after the calibration solutions.

\section{Calculation}

5.1. Calculate the phosphorus content $(\mathrm{mg})$ in each $100 \mu \mathrm{L}$ of calibration stock solution [E]. (The value should be between 0.102 and $0.107 \mathrm{mg}$.)

$$
\mathrm{E}=\mathrm{F} \times \frac{30.974}{136.09} \times \frac{1}{1000}
$$

5.2. Calculate the phosphorus content $(\mathrm{mg})$ in calibration point 1,2 and 3 .

$\mathrm{X}_{1}, \mathrm{mg}=\mathrm{E} \quad=$ Phosphorus content in calibration point 1

$\mathrm{X}_{2}, \mathrm{mg}=3 \times \mathrm{E} \quad=$ Phosphorus content in calibration point 2

$\mathrm{X}_{3}, \mathrm{mg}=5 \mathrm{xE} \quad=$ Phosphorus content in calibration point 3

5.3. Plot a line using phosphorus content ( $\mathrm{mg}, \mathrm{x}$ axis) versus absorbance (y axis). Include the blank solution. If the points do not form a line with a linear correlation 0.998 or better, repeat the test. Calculate the y-intercept, slope and correlation of the points for the line. 


\section{Appendix B. Preparation of Vanadate-molybdate Reagent}

\section{Introduction}

\subsection{Description}

This appendix describes how to prepare the colorimetric reagent for phosphorus analysis. This procedure is based on method 4500-P C in Standard Methods for the Examination of Water and Wastewater, 17th Edition.

\subsection{Reference Documents}

1.2.1. Standard Methods for the Examination of Water and Wastewater, 17th edition. American Public Health Association. Washington, D.C., 1989.

1.2.2. Document \# QA-0004 -- Inspection and Test Equipment Control

\section{Preparation}

Note: Persons performing this procedure are responsible for knowing and observing proper safety precautions for the chemicals. Safety precaution information is given in the MSDS for each chemical.

2.1. Get equipment. If glassware is not clean, wash it with NOCHROMIX solution. DO NOT CLEAN THE GLASSWARE WITH SOAP OR DETERGENT.

Glassware must be phosphate free!

2.1.1. $1000 \mathrm{~mL}$ volumetric flask (Class A, calibrated, record ID\# to notebook)

2.1.2. Two $1 \mathrm{~L}$ beakers (Calibration is not required)

2.1.3. $500 \mathrm{~mL}$ graduated cylinder (Calibration is not required)

2.1.4. $1 \mathrm{~L}$ glass stock bottle (Calibration is not required)

2.1.5. A balance (calibrated, accurate to $0.001 \mathrm{~g}$, e.g. Mettler, Model PM400)

Note: Calibration procedures are specified in Inspection and Test Equipment Control, document \# QA-0004.

2.2. Get reagents

2.2.1. Ammonium molybdate, $\left(\mathrm{NH}_{4}\right)_{6} \mathrm{Mo}_{7} \mathrm{O}_{24} \bullet 4 \mathrm{H}_{2} \mathrm{O}(99 \%)$, reagent grade

2.2.2. Ammonium metavanadate, $\mathrm{NH}_{4} \mathrm{VO}_{3}(99 \%)$, reagent grade (or sodium metavanadate, $90 \%$ )

2.2.3. DI water (ASTM Type I)

2.2.4. Concentrated $\mathrm{HCl}$, reagent grade 


\section{Procedure}

3.1. Solution A: Dissolve 25 grams of $\left(\mathrm{NH}_{4}\right)_{6} \mathrm{Mo}_{7} \mathrm{O}_{24} \bullet 4 \mathrm{H}_{2} \mathrm{O}$ in $300 \mathrm{~mL}$ DI water in a 1 L beaker.

3.2. Solution B:

3.2.1. Weigh 1.28 grams of $\mathrm{NH}_{4} \mathrm{VO}_{3}$ into a $1 \mathrm{~L}$ beaker.

3.2.2. Dissolve the $\mathrm{NH}_{4} \mathrm{VO}_{3}$ in $300 \mathrm{~mL}$ DI water by heating to boiling.

3.2.3. Cool solution to room temperature.

3.2.4. Add $330 \mathrm{~mL}$ Concentrated $\mathrm{HCl}$ to solution.

3.2.5. Cool the solution to room temperature.

3.2.6. Transfer the solution to a $1000 \mathrm{~mL}$ volumetric flask.

3.3. Pour solution A into Solution B, mix well and dilute to $1000 \mathrm{~mL}$ mark.

3.4. Transfer the reagent to a $1 \mathrm{~L}$ bottle. Label the bottle with the date, contents, and the notebook reference. The solution is good for three months when stored at ambient conditions in a glass container.

\section{Records}

4.1. Record the quantity and source of each component used to make this solution in a notebook. 


\section{Flame AA Standard Operating Procedure}

\section{Introduction}

\subsection{Description}

This document describes the operation of the FAAS, including preventive maintenance and calibration activities, at Eichrom Industries. It applies to all facilities that operate a FAAS.

\subsection{Definitions}

1.2.1. FAAS:Flame Atomic Absorption Spectrometer

1.2.2. HCL: Hollow Cathode Lamp

\subsection{Reference Documents}

1.3.1. Document \#QA-0004 -- Control of Inspection and Test Equipment

1.3.2. Document \#GEN-0010 -- Control of Quality Records

\subsubsection{Model 3110 Atomic Absorption Spectrometer Hardware} Guide. Perkin Elmer. Part Number 0993-8863, Release C, October 1995. Published in the USA.

1.3.4. Analytical Methods for Atomic Absorption Spectroscopy. Perkin Elmer. Part Number 0303-0152, Release C, August 1994. Published in the USA.

\subsubsection{Concepts, Instrumentation, and Techniques in Atomic} Absorption Spectroscopy. Perkin Elmer. Part Number 09939533, Release B, 1993. Published in the USA.

1.3.6. Appendices contain standard conditions and parameters for specific analytes.

\section{Preparation}

2.1. Read MSDS sheets for chemicals listed in 2.3.

\subsection{Equipment}

2.2.1. FAAS.

2.2.2. Burner Head (acetylene or $\mathrm{N}_{2} \mathrm{O}$ )

2.2.3. Hollow Cathode Lamps (HCLs)

2.2.4. Class A volumetric flasks, if dilution required.

2.2.5. $1 \mathrm{~mL}$ adjustable autopipettor (calibrated, record ID number in laboratory notebook) and pipet tips.

2.2.6. $5 \mathrm{~mL}$ adjustable autopipettor (calibrated, record ID number in laboratory notebook) and pipet tips.

\subsection{Chemicals}

2.3.1. Metal standards for element(s) of interest. 
2.3.2. Calibration Verification Standards for component(s) of interest. If using previously prepared standards, ensure that standards are less than 90 days old, and that enough standard exists for at least two runs. If not, prepare new standards. Newly prepared standards shall be compared with the standards which they are replacing, if available. The preparation of standards is recorded in the QC/Maintenance Log.

\subsubsection{Samples}

2.3.4. Distilled or Deionized water, ASTM Type I

2.3.5. Acetylene Gas, AA Grade

2.3.6. Nitrous Oxide Gas, AA Grade

2.3.7. $\mathrm{KCl}$ for controlling ionization interferences

\subsection{Safety Equipment}

2.4.1. Disposable gloves, with appropriate chemical resistance

2.4.2. Safety glasses

2.4.3. Lab jacket

\section{Procedures}

\subsection{Safety Checks}

\subsubsection{General}

3.1.1.1.Turn the vent on and ensure it is properly drawing before proceeding.

3.1.1.2. Close the flame door.

3.1.1.3.Ensure cylinders contain sufficient gas for the intended analysis.

3.1.1.4.Ensure a fire extinguisher is located near the equipment and ensure it is charged.

\subsubsection{Burner Head}

3.1.2.1.Ensure the proper burner head has been selected for the samples.

3.1.2.2.If changing the burner head, ensure the O-ring is in good condition. If the O-ring is damaged, replace it.

3.1.2.3.Ensure the burner head slot is clean.

3.1.2.4.Ensure the burner head is fully seated into the spray chamber, and secure the restraining cables and the interlock pin.

\subsubsection{Drain System}

3.1.3.1.Ensure the drain system has been properly installed.

3.1.3.2.If the level of waste in the drain vessel is high, properly dispose of the waste and reassemble the drain system. See section 7 for disposal guidelines. 


\subsection{Parameters}

This section describes each of the parameters. The parameter settings for the elements are specified in the appendices to this procedure.

3.2.1. Lamp Current - Set this to the appropriate value, in $\mathrm{mA}$, for the desired element to be tested.

3.2.2. Integration Time - The time the FAAS waits between sample replicates. Set to 1 second for quality procedures.

3.2.3. Replicates - The number of sample replicates. Set to 10 for quality control procedures.

3.2.4. Calibration Type - Linear, non-linear, or method of additions. Use the default value, non-linear, for quality procedures.

3.2.5. AA Technique - Flame, PK area, Peak height. The default is Flame, and this is the only option available on our 3110 model.

3.2.6. Standards $1-8$ - You have the option of using up to 8 standards. Three standards are the minimum. The decimal point is automatically set based on the first standard entered.

3.2.7. Reslope Standard - resets the calibration line based on the value entered. Do not use this option.

3.2.8. Read Delay Time - The spectrometer will delay reading the signal of the aspirated sample for the specified time. Use the default value, 0 .

3.2.9. Print Calibration Curve - Default value is Yes. Set this parameter to No because the FAAS has no printer attached.

\subsection{Calibration}

Additional details and guidelines for calibration of the FAAS are on pages 119121 of Model 3110 Atomic Absorption Spectrometer Hardware Guide.

3.3.1. The calibration consists of a blank and at least three standards.

3.3.2. S1 should be equal to the high end of the linear range, $\mathrm{S} 2$ is three times $\mathrm{S} 1$, and $\mathrm{S} 3$ is six times $\mathrm{S} 1$. For additional explanation, refer to pages 16-23 of the Analytical Methods for Atomic Absorption Spectrometry.

3.3.3. Standards should be matrix matched to the samples being run for best results.

3.3.4. The FAAS software automatically creates a calibration curve.

3.3.5. Re-analyze standards as samples during runs.

\subsection{Igniting and optimizing the FAAS}

\subsubsection{Turn on the FAAS.}

3.4.2. Dial the wavelength to the appropriate setting for the element to be analyzed. Use the first wavelength listed unless another is required. Record deviations in the QC/Maintenance Log. 
3.4.3. Set the slit width to the correct setting for the element being analyzed, as specified in the appendices. Record deviations in the QC/Maintenance Log.

3.4.4. Install the applicable HCL into the lamp holder and set the lamp current to the correct $\mathrm{mA}$ for the element being tested. Record the HCL energy in the QC/Maintenance Log.

3.4.5. Align the lamp to achieve the maximum energy.

3.4.6. Turn on the gas supply at the tanks.

3.4.7. Adjust the burner height.

3.4.8. Ignite the flame.

3.4.9. Adjust the horizontal and rotational position of the burner.

3.4.10. Adjust the nebulizer.

3.4.11. Record the energy level in QC/Maintenance Log.

3.4.12. Autozero the instrument in the Continuous Mode using deionized water. Then check the characteristic concentration solution and record the absorbance value in the QC/Maintenance Log.

3.4.13. Record the date and analyst's initials next to the entries in the QC/Maintenance Log.

\subsection{Running Samples}

Samples must be bracketed by the standards. If the samples are beyond the range of the standards, dilute the samples or prepare a new set of standards bracketing the samples.

3.5.1. Prepare solutions.

3.5.2. Enter parameters. The parameters are specified in the appendix for the element.

3.5.3. Enter the data collection mode.

3.5.4. Run the standard blank.

3.5.5. Run the standards.

3.5.6. Analyze DI water between the standards and the samples. Also analyze DI water before and after each check standard.

3.5.7. Run the samples.

3.5.8. Re-analyze the standards after every set of 10 samples. If the standards deviate by more than $20 \%$, recalibrate and rerun the last batch of samples.

3.5.9. Run one duplicate sample for every set of 10 samples run. If duplicate value deviates by more than $20 \%$, recalibrate and rerun the batch of samples. 


\subsection{Powering Down the System}

3.6.1. Aspirate de-ionized water for a few minutes to clean the burner head.

3.6.2. Turn the gas control switch on the pneumatics control panel to OFF.

3.6.3. Close all gas source valves.

3.6.4. Turn the gas control switch to Air to allow acetylene and oxidant to bleed.

3.6.5. Turn the gas control switch to OFF.

3.6.6. Turn the instrument OFF.

3.6.7. Turn the vent OFF.

\section{Calculations}

4.1. Calculate metal concentration in the sample using the following equation:

$\mathbf{p p m}=\mathbf{C} \times \mathbf{D}$

Where: $\quad \mathrm{ppm}=$ The actual concentration of metal in the sample. $(\mathrm{ppm})$

$\mathrm{C}=$ The reading from the FAAS. (ppm)

$\mathrm{D}=$ The dilution factor.

5. Maintenance

\subsection{Burner Head}

5.1.1. Clean burner head at least monthly. Record in QC/Maintenance Log.

5.1.2. If aspirating samples with high solids content, clean the burner daily. Record in QC/Maintenance Log.

5.1.3. Clean the slot in the burner with the thin metal strip provided with the instrument before each use. Record in QC/Maintenance Log.

5.1.4. The burner head can also be soaked overnight in a mild detergent and then rinsed with deionized water and blown dry.

\subsection{Air compressor}

5.2.1. Drain the air compressor of water monthly. Record in QC/Maintenance Log.

\section{Sample Retention and Disposal}

6.1. Retain samples for metal analyses one month (30 days). Retain samples longer when requested by the client. Identify each collection of samples so the contents of the samples can be identified. Mark disposal date on each collection of samples.

6.2. Segregate samples for disposal by matrix type. Collect waste in 5 gallon or smaller containers, as appropriate for the expected volume during a 180 day period.

6.3. Separate RCRA listed metals from the other metals. 
6.4. Label each waste storage container with its contents and start date.

\section{7. $\quad$ Records}

7.1. Record all data in a lab notebook. Record Maintenance and HCL energy in QC/Maintenance Log.

7.2. Data should include the element tested, wavelength, slit width, and the energy of the HCL.

\section{List of Appendices}

8.1. Appendix A - Europium

8.2. Appendix B - Strontium

8.3. Appendix C - Nickel

8.4. Appendix D - Lead

8.5. Appendix E - Iron 


\section{Appendix E - Iron}

Standard Atomic Absorption Conditions for Fe

\begin{tabular}{|c|c|c|c|c|c|}
\hline Wavelength & $(\mathrm{nm})$ & $\begin{array}{l}\text { Relative } \\
\text { Noise }\end{array}$ & $\begin{array}{c}\text { Characteristic } \\
\text { Concentration } \\
(\mathrm{mg} / \mathrm{L})\end{array}$ & $\begin{array}{c}\text { Characteristic } \\
\text { Concentration } \\
\text { Check } \\
(\mathrm{mg} / \mathrm{L})\end{array}$ & $\begin{array}{l}\text { Linear } \\
\text { Range } \\
(\mathrm{mg} / \mathrm{L})\end{array}$ \\
\hline 248.3 & 0.2 & 1.0 & 0.11 & 6.0 & 6.0 \\
\hline
\end{tabular}

1. Use an Air - Acetylene flame.

2. Use calibration standards of 5, 10, and $15 \mathrm{ppm}$ Fe.

\section{Parameters}

Lamp Current $\quad 60 \mathrm{~mA}$

Integration time $1 \mathrm{sec}$.

Replicates $\quad 10$

Calibration Type non-linear

AA Technique flame

Read Delay Time $0 \mathrm{sec}$. 
Appendix B 
Example Data Logger Table

\begin{tabular}{|c|c|c|c|c|l|}
\hline Time & $\begin{array}{c}\text { Rxn } \\
\text { Temp } \\
{ }^{\circ} \mathrm{C}\end{array}$ & $\begin{array}{c}\text { Heater } \\
\text { Temp. } \\
{ }^{\circ} \mathrm{C}\end{array}$ & $\begin{array}{c}{ }^{\circ} \mathrm{C} \\
{ }^{\circ} \mathrm{C}\end{array}$ & \\
\hline $10 / 16 / 9717: 27$ & 53.4 & 55.3 & 54.5 & 55.3 & \\
\hline $10 / 16 / 9717: 42$ & 51.9 & 60.9 & 59.5 & 57.6 & \\
\hline $10 / 16 / 9717: 57$ & 53.6 & 68.6 & 67.1 & 65.3 & \\
\hline $10 / 16 / 9718: 12$ & 57.2 & 74.6 & 72.9 & 71.4 & \\
\hline $10 / 16 / 9718: 27$ & 61.7 & 79.9 & 78.3 & 76.8 & \\
\hline $10 / 16 / 9718: 42$ & 66.1 & 75.9 & 74.7 & 76.0 & \\
\hline $10 / 16 / 9718: 57$ & 68.1 & 73.0 & 71.8 & 73.2 & \\
\hline $10 / 16 / 9719: 12$ & 68.5 & 71.3 & 70.1 & 71.4 & \\
\hline $10 / 16 / 9719: 27$ & 67.7 & 69.9 & 68.7 & 70.1 & \\
\hline $10 / 16 / 9719: 42$ & 67.3 & 79.2 & 77.4 & 76.2 & \\
\hline $10 / 16 / 9719: 57$ & 69.2 & 78.9 & 76.9 & 75.9 & \\
\hline $10 / 16 / 9720: 12$ & 71.7 & 84.4 & 82.6 & 81.5 & \\
\hline $10 / 16 / 9720: 27$ & 74.8 & 83.8 & 82.7 & 83.9 & \\
\hline $10 / 16 / 9720: 42$ & 76.6 & 80.9 & 79.4 & 80.9 & \\
\hline $10 / 16 / 9720: 57$ & 76.7 & 79.0 & 77.6 & 79.1 & \\
\hline $10 / 16 / 9721: 12$ & 75.4 & 77.2 & 75.9 & 77.3 & \\
\hline $10 / 16 / 9721: 27$ & 74.0 & 81.6 & 79.6 & 78.4 & \\
\hline $10 / 16 / 9721: 42$ & 74.6 & 83.8 & 82.4 & 83.7 & \\
\hline $10 / 16 / 9721: 57$ & 75.6 & 79.7 & 78.3 & 79.8 & \\
\hline $10 / 16 / 9722: 12$ & 75.2 & 77.3 & 76.0 & 77.4 & \\
\hline $10 / 16 / 9722: 27$ & 74.2 & 85.4 & 83.5 & 82.3 & \\
\hline $10 / 16 / 9722: 42$ & 75.4 & 81.0 & 79.6 & 81.0 & \\
\hline $10 / 16 / 9722: 57$ & 75.3 & 78.2 & 76.8 & 78.2 & \\
\hline $10 / 16 / 9723: 12$ & 74.3 & 83.5 & 81.4 & 80.4 & \\
\hline $10 / 16 / 9723: 27$ & 75.3 & 81.9 & 80.4 & 81.8 & \\
\hline $10 / 16 / 9723: 42$ & 75.6 & 78.7 & 77.2 & 78.7 & \\
\hline $10 / 16 / 9723: 57$ & 74.4 & 81.7 & 79.8 & 78.8 & \\
\hline $10 / 17 / 970: 12$ & 75.0 & 83.1 & 81.6 & 83.1 & \\
\hline $10 / 17 / 970: 27$ & 75.7 & 79.3 & 77.9 & 79.4 & \\
\hline $10 / 17 / 970: 42$ & 74.9 & 77.0 & 75.6 & 77.1 & \\
\hline $10 / 17 / 970: 57$ & 74.5 & 87.6 & 85.6 & 84.6 & \\
\hline $10 / 17 / 971: 12$ & 75.8 & 80.2 & 78.8 & 80.3 & \\
\hline $10 / 17 / 971: 27$ & 75.2 & 77.6 & 76.3 & 77.8 & \\
\hline $10 / 17 / 971: 42$ & 74.3 & 85.2 & 83.1 & 82.0 & \\
\hline $10 / 17 / 971: 57$ & 75.3 & 80.9 & 79.5 & 80.9 & \\
\hline $10 / 17 / 972: 12$ & 75.2 & 78.0 & 76.7 & 78.0 & \\
\hline $10 / 17 / 972: 27$ & 74.3 & 85.4 & 83.4 & 82.2 & \\
\hline
\end{tabular}




\begin{tabular}{|l|l|l|l|l|l|}
\hline $10 / 17 / 972: 42$ & 75.4 & 80.9 & 79.4 & 80.9 & \\
\hline $10 / 17 / 972: 57$ & 75.3 & 78.0 & 76.6 & 78.1 & \\
\hline $10 / 17 / 973: 12$ & 74.3 & 84.1 & 82.1 & 81.0 & \\
\hline $10 / 17 / 973: 27$ & 75.3 & 82.3 & 80.9 & 82.3 & \\
\hline $10 / 17 / 973: 42$ & 75.7 & 78.9 & 77.6 & 79.0 & \\
\hline $10 / 17 / 973: 57$ & 74.7 & 79.8 & 77.4 & 76.8 & \\
\hline $10 / 17 / 974: 12$ & 74.6 & 88.1 & 85.9 & 84.9 & \\
\hline $10 / 17 / 974: 27$ & 75.8 & 80.5 & 79.1 & 80.6 & \\
\hline $10 / 17 / 974: 42$ & 75.3 & 77.8 & 76.4 & 77.9 & \\
\hline $10 / 17 / 974: 57$ & 74.3 & 84.4 & 82.4 & 81.3 & \\
\hline $10 / 17 / 975: 12$ & 75.3 & 81.8 & 80.4 & 81.8 & \\
\hline $10 / 17 / 975: 27$ & 75.6 & 78.6 & 77.2 & 78.7 & \\
\hline $10 / 17 / 975: 42$ & 74.4 & 83.1 & 80.9 & 79.9 & \\
\hline $10 / 17 / 975: 57$ & 74.7 & 82.8 & 81.3 & 82.7 & \\
\hline $10 / 17 / 976: 12$ & 75.2 & 78.9 & 77.5 & 79.0 & \\
\hline $10 / 17 / 976: 27$ & 74.3 & 76.7 & 75.3 & 76.8 & \\
\hline $10 / 17 / 976: 42$ & 74.3 & 87.6 & 85.5 & 84.4 & \\
\hline $10 / 17 / 976: 57$ & 75.4 & 80.1 & 78.6 & 80.2 & \\
\hline $10 / 17 / 977: 12$ & 75.2 & 77.7 & 76.3 & 77.9 & \\
\hline $10 / 17 / 977: 27$ & 74.1 & 84.7 & 82.8 & 81.7 & \\
\hline $10 / 17 / 977: 42$ & 75.2 & 81.2 & 79.8 & 81.3 & \\
\hline $10 / 17 / 977: 57$ & 75.2 & 78.3 & 76.9 & 78.4 & \\
\hline $10 / 17 / 978: 12$ & 74.3 & 82.7 & 80.8 & 79.8 & \\
\hline $10 / 17 / 978: 27$ & 75.1 & 82.6 & 81.2 & 82.7 & \\
\hline $10 / 17 / 978: 42$ & 75.5 & 79.1 & 77.7 & 79.2 & \\
\hline $10 / 17 / 978: 57$ & 74.6 & 79.9 & 77.8 & 77.1 & \\
\hline $10 / 17 / 979: 12$ & 74.8 & 82.6 & 81.2 & 82.7 & \\
\hline $10 / 17 / 979: 27$ & 74.9 & 78.8 & 77.5 & 78.9 & \\
\hline $10 / 17 / 979: 42$ & 74.4 & 82.9 & 80.8 & 79.8 & \\
\hline $10 / 17 / 979: 57$ & 75.1 & 81.4 & 80.2 & 81.6 & \\
\hline $10 / 17 / 9710: 12$ & 75.6 & 78.7 & 77.4 & 78.8 & \\
\hline $10 / 17 / 9710: 27$ & 74.7 & 80.0 & 77.5 & 76.8 & \\
\hline $10 / 17 / 9710: 42$ & 74.9 & 82.4 & 81.1 & 82.4 & \\
\hline $10 / 17 / 9710: 57$ & 75.6 & 79.0 & 77.7 & 79.2 & \\
\hline $10 / 17 / 9711: 12$ & 75.0 & 77.1 & 75.8 & 77.2 & \\
\hline $10 / 17 / 9711: 27$ & 74.5 & 87.2 & 85.2 & 84.1 & \\
\hline $10 / 17 / 9711: 42$ & 75.7 & 80.1 & 78.7 & 80.1 & \\
\hline $10 / 17 / 9711: 57$ & 75.3 & 77.8 & 76.4 & 77.9 & \\
\hline $10 / 17 / 9712: 12$ & 74.4 & 84.9 & 83.0 & 81.8 & \\
\hline $10 / 17 / 9712: 27$ & 75.6 & 80.9 & 79.6 & 80.8 & \\
\hline $10 / 17 / 9712: 42$ & 75.6 & 78.2 & 76.9 & 78.3 & \\
\hline $10 / 17 / 9712: 57$ & 74.6 & 76.4 & 75.2 & 76.5 & \\
\hline $10 / 17 / 9713: 12$ & 73.2 & 74.8 & 73.6 & 74.8 & \\
\hline & & & & & \\
\hline
\end{tabular}




\begin{tabular}{|l|l|l|l|l|l|}
\hline $10 / 17 / 9713: 27$ & 71.6 & 73.2 & 72.0 & 73.3 & \\
\hline $10 / 17 / 9713: 42$ & 70.2 & 71.7 & 70.6 & 71.8 & \\
\hline $10 / 17 / 9713: 57$ & 68.7 & 70.3 & 69.2 & 70.4 & \\
\hline $10 / 17 / 9714: 12$ & 67.4 & 69.0 & 67.9 & 69.0 & \\
\hline $10 / 17 / 9714: 27$ & 66.1 & 67.7 & 66.6 & 67.8 & \\
\hline $10 / 17 / 9714: 42$ & 65.0 & 66.5 & 65.4 & 66.6 & \\
\hline $10 / 17 / 9714: 57$ & 63.7 & 65.2 & 64.2 & 65.3 & \\
\hline $10 / 17 / 9715: 12$ & 62.4 & 64.0 & 63.0 & 64.1 & \\
\hline $10 / 17 / 9715: 27$ & 61.3 & 62.8 & 61.8 & 62.9 & \\
\hline $10 / 17 / 9715: 42$ & 59.8 & 61.6 & 60.7 & 61.7 & \\
\hline
\end{tabular}


Appendix C 


\section{Silica-Based Diphonix Resin Manufacture Flowsheet}
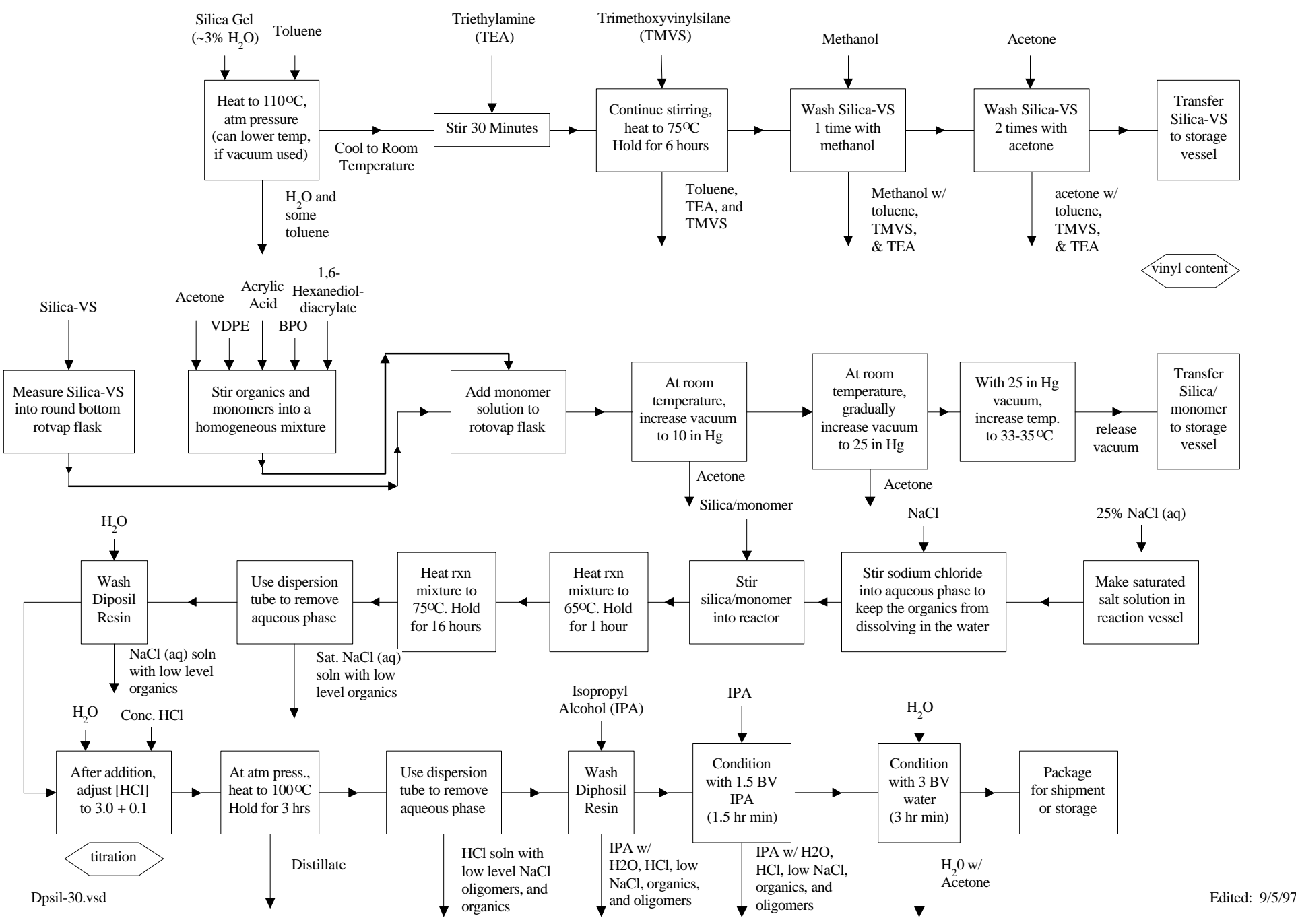


\section{Silica-Based Diphonix Resin -- Surface Modification: Equipment Table}

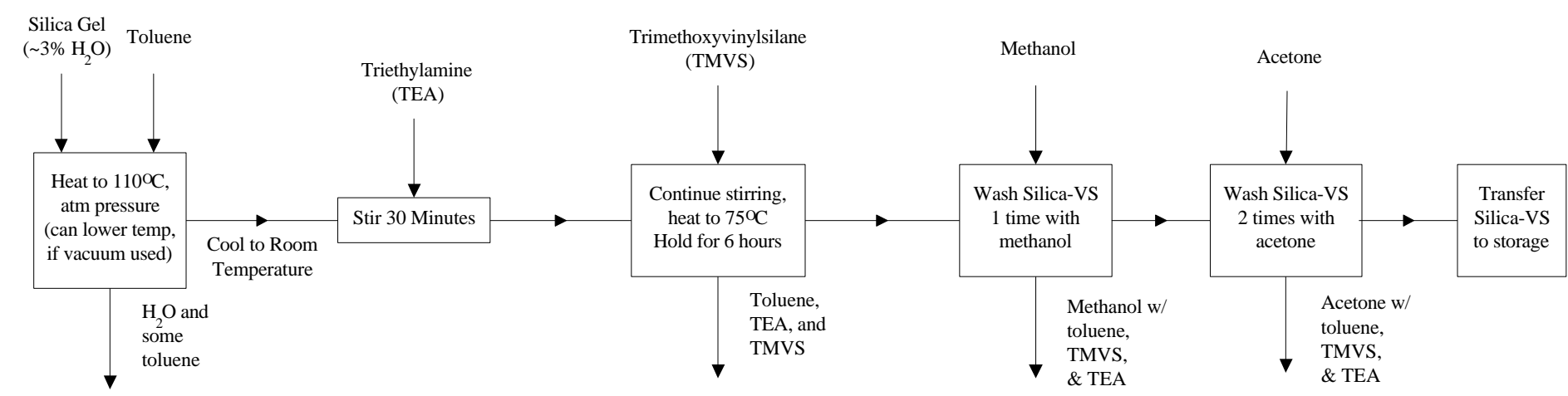

Equipment

Reaction Vesse (Closed)

Vacuum Pump

Heating System

Condenser

Dean-Stark type trap

\section{PPE / Mechanical} Controls

\begin{tabular}{|c|c|}
\hline $\begin{array}{l}\text { Respirator (Organic + } \\
\text { Dust) }\end{array}$ & Respirator (Organic) \\
\hline Safety Goggles & Safety Goggles \\
\hline $\begin{array}{l}\text { Chemical resistant } \\
\text { gloves }\end{array}$ & $\begin{array}{l}\text { Chemical resistant } \\
\text { gloves }\end{array}$ \\
\hline Protective Clothing & $\begin{array}{l}\text { Protective Clothing } \\
\text { Faceshield ( } 8 \text { " min.) }\end{array}$ \\
\hline Chemical Fume Hood & Chemical Fume Hooc \\
\hline Safety Shower & Safety Shower \\
\hline Eye Wash & Eye Wash \\
\hline
\end{tabular}

Equipment

Reaction Vessel (Open)

Heating System

Condenser

PPE / Mechanical Controls

Respirator (Organic)

Safety Goggles

Chemical resistant

gloves

Protective Clothing

Faceshield (8" min.)

Chemical Fume Hood

Safety Shower

Eye Wash
Equipment

Reaction Vessel

(Open)

Vacuum Pump

Reaction Vesse (Open)

Vacuum Pump

Equipment

Transfer Pump

Collection Vessel

Dispersion Tube Dispersion Tube

Collection Flask Collection Flask

PPE / Mechanical PPE / Mechanical PPE / Mechanical Controls

Controls

Controls

Respirator (Organic) Respirator (Organic) Respirator (Organic)

Safety Goggles Safety Goggles Safety Goggles

Chemical resistant Chemical resistant Chemical resistant

gloves gloves

gloves

Protective Clothing Protective Clothing Protective Clothing

Chemical Fume Hood Chemical Fume Hood Chemical Fume Hood Safety Shower Safety Shower Safety Shower

Eye Wash $\quad$ Eye Wash Eye Wash 


\section{Silica-Based Diphonix Resin -- Polymerization Preparation: Equipment Table}

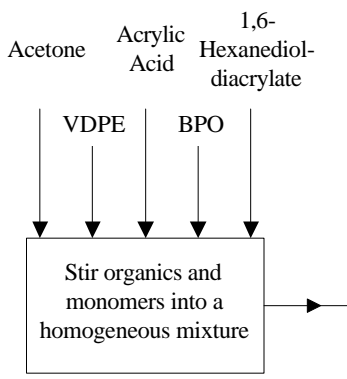

Equipment

Reaction Vessel

(Open?)

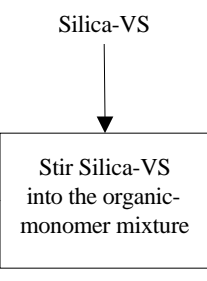

Equipment

Reaction Vessel

(Open)

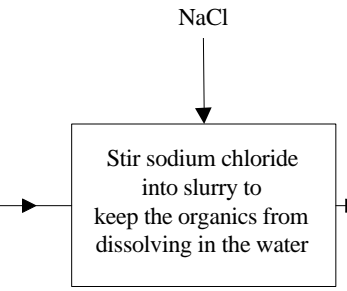

Equipment
Reaction Vessel (Open)

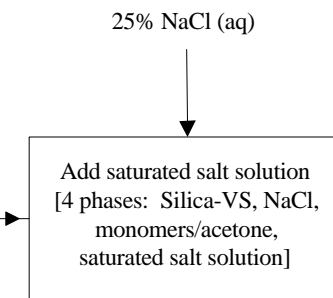

Equipment

Reaction Vessel

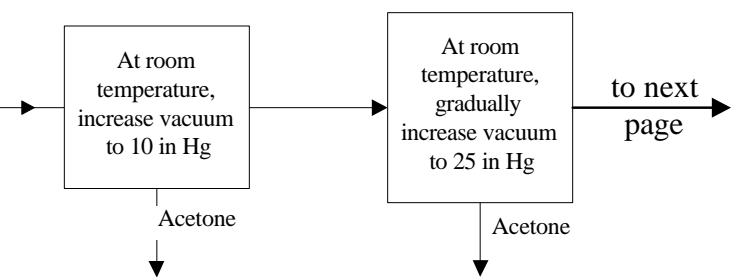

Equipment

$\begin{array}{ll}\begin{array}{l}\text { Reaction Vessel } \\ \text { (Closed) }\end{array} & \begin{array}{l}\text { Reaction Vessel } \\ \text { (Closed) } \\ \text { Vacuum Pump }\end{array} \\ \text { Vacuum Pump } \\ \begin{array}{l}\text { Condenser } \\ \text { Distillation Head }\end{array} & \begin{array}{l}\text { Condenser } \\ \text { Distillation Head }\end{array}\end{array}$

Distillation Head

\section{PPE / Mechanical}

Controls

$\begin{aligned} & \text { Respirator } \\ & \text { (Organic) }\end{aligned}$
Safety Goggles
Chemical resistant
gloves
Protective
Clothing
8" min Faceshield
Chemical Fume
Hood
Safety Shower
Eye Wash

Respirator

Safety Goggles

Clothing

Safety Shower

Eye Wash

PPE / Mechanical
Controls
Respirator
(Organic + Dust)
Safety Goggles
Chemical resistant
gloves
Protective
Clothing
8" min Faceshield

Chemical Fume
Hood
Safety Shower
Eye Wash

PPE / Mechanical Controls

Respirator
(Organic)
Safety Goggles
Chemical resistan
gloves
Protective
Clothing
8" min Faceshield
Chemical Fume
Hood
Safety Shower
Eye Wash

PPE / Mechanical
Controls
Respirator
(Organic)
Safety Goggles
Chemical resistant
gloves
Protective
Clothing

Chemical Fume
Hood
Safety Shower
Eye Wash

PPE / Mechanical Controls
Respirator
(Organic)
Safety Goggles
Chemical resistant
gloves
Protective
Clothing
Chemical Fume
Hood
Safety Shower
Eye Wash 


\section{Silica-Based Diphonix Resin -- Polymerization: Equipment Table}

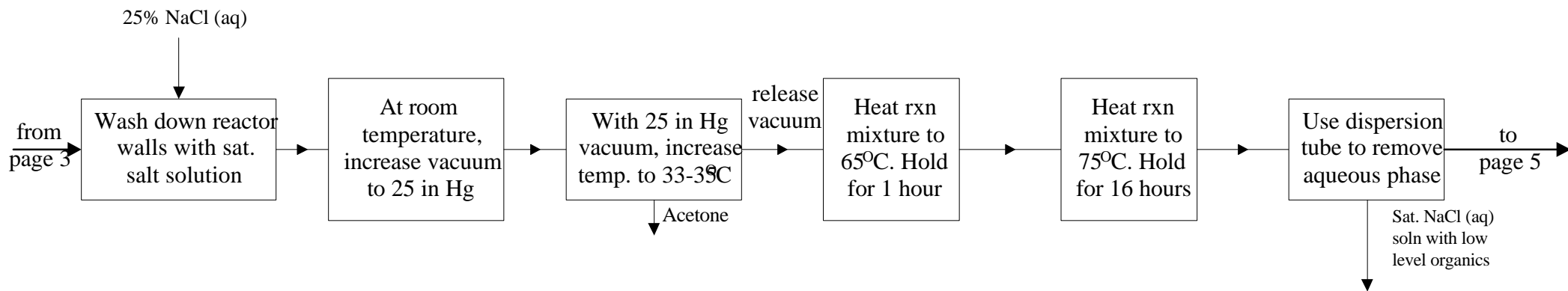

Equipment

Reaction Vessel

(Open)

\section{Equipment}

Reaction Vessel
(Closed)

Vacuum Pump

Condenser

Distillation Head
Equipment

Reaction Vessel

(Closed)

Vacuum Pump

Heater

Condenser

Distillation Head

PPE / Mechanical Controls

Respirator

(Organic)

Safety Goggles

Chemical resistant

gloves

Protective

Clothing

Chemical Fume

Hood

Eye Wash

Hood
Safety Shower
Eye Wash

Cume

Eye Wash
Hood

Safety Shower

Eye Wash
Equipment

Reaction Vessel
(Open?)

Heater

Condenser?

Equipment

$\begin{array}{lll}\begin{array}{l}\text { PPE / Mechanical } \\ \text { Controls }\end{array} & \begin{array}{l}\text { PPE / Mechanical } \\ \text { Controls }\end{array} & \begin{array}{l}\text { PPE / Mechanical } \\ \text { Controls }\end{array} \\ \begin{array}{lll}\text { Respirator } \\ \text { (Organic) }\end{array} & \begin{array}{l}\text { Respirator } \\ \text { (Organic) }\end{array} & \begin{array}{l}\text { Respirator } \\ \text { (Organic) }\end{array} \\ \text { Safety Goggles } & \text { Safety Goggles } & \text { Safety Goggles } \\ \text { Chemical resistant } & \text { Chemical resistant } & \text { Chemical resistant } \\ \text { gloves } & \text { gloves } & \text { gloves } \\ \text { Protective } & \text { Protective } & \text { Protective } \\ \text { Clothing } & \text { Clothing } & \text { Clothing }\end{array}$

Chemical Fume

Hood

Safety Shower

Eye Wash
Reaction Vessel
(Open?)

Heater

Condenser?

Dispersion Tube
Collection Flask

Equipment

Reaction Vessel

Vacuum Pump

$\begin{array}{ll}\text { Chemical Fume } & \text { Chemical Fume } \\ \text { Hood } & \text { Hood } \\ \text { Safety Shower } & \text { Safety Shower } \\ \text { Eye Wash } & \text { Eye Wash }\end{array}$




\section{Silica-Based Diphonix Resin -- Hydrolysis: Equipment Table}
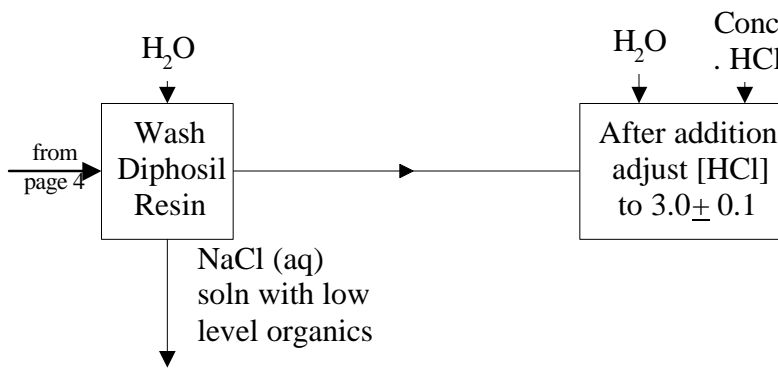

After addition

adjust $[\mathrm{HCl}]$

to $3.0 \pm 0.1$

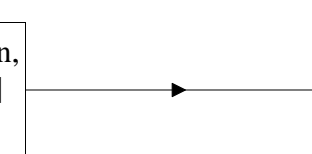

At atm press.,
heat to $10{ }^{\circ} \mathrm{C}$

Hold for $3 \mathrm{hrs}$

Use dispersion \begin{tabular}{l|c} 
& to \\
&
\end{tabular} aqueous phase

$\mathrm{HCl}$ soln with low level $\mathrm{NaCl}$ oligomers, and

Equipmen

Reaction Vessel

(Open)

/ Mechanical

Controls

Respirator

(Organic)

Safety Goggles

Chemical resistant

gloves

Protective

Clothing

Chemical Fume

Hood

Safety Shower

Eye Wash

\section{Equipment}

Reaction Vessel

(Open)
Equipment

Reaction Vesse

(Open?)

Heater

Condenser?

PPE / Mechanical

Controls

Respirator (Acid

+ Organic)

Safety Goggles

Chemical resistant

gloves

Protective

Clothing

Chemical Fume

Hood

Safety Shower

Eye Wash
Equipment

Reaction Vessel
(Open)

Vacuum Pump

Dispersion Tube Collection Flask

PPE / Mechanical Controls

Respirator (Acid + Organic)

Safety Goggles

Chemical resistant

gloves

Protective

Clothing

Chemical Fume

Hood

Safety Shower

Eye Wash
Safety Shower

Eye Wash 


\section{Silica-Based Diphonix Resin -- Conditioning: Equipment Table}

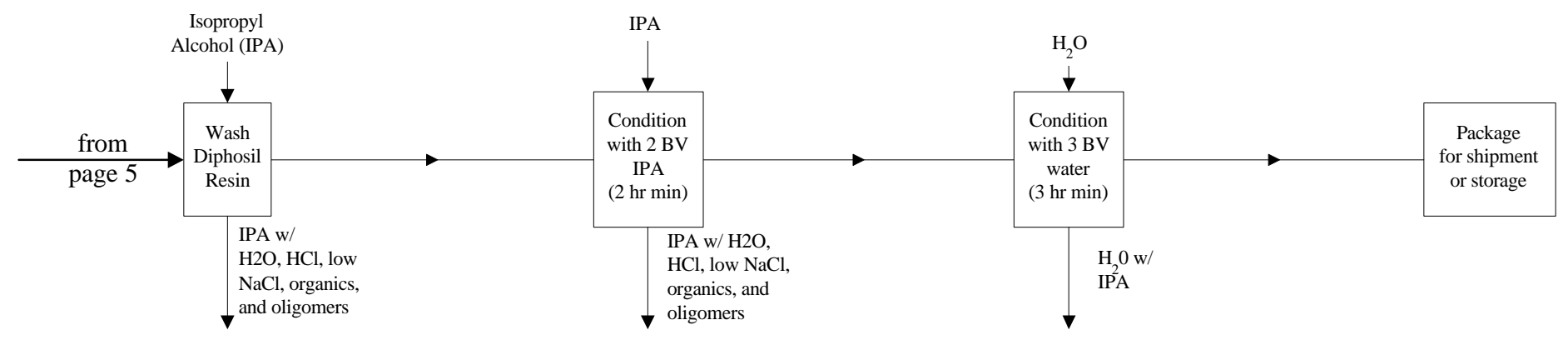

\section{Equipment}

Reaction Vessel

(Open)
Equipment

Conditioning Tank

(Open)
Equipment

Conditioning Tank

(Open)
Equipment

Balance

Packaging

Materials

Scoop?

\section{PPE / Mechanical}

Controls

Respirator

(Organic)

Safety Goggles

Chemical resistant

gloves

Protective

Clothing

Chemical Fume

Hood

Safety Shower

Eye Wash
PPE / Mechanical

Controls

\section{Respirator}

(Organic)

Safety Goggles

Chemical resistant

gloves

Protective

Clothing

Chemical Fume

Hood

Safety Shower

Eye Wash
PPE / Mechanical

Controls

Safety Goggles

Chemical resistant

gloves

Protective

Clothing

Safety Shower

Eye Wash
PPE / Mechanical

Controls

Dust Mask

Safety Glasses

Chemical resistant

gloves

Protective

Clothing

Safety Shower

Eye Wash 